NBER WORKING PAPER SERIES

\title{
BEYOND COMPETITIVE DEVALUATIONS: THE MONETARY DIMENSIONS OF COMPARATIVE ADVANTAGE
}

\author{
Paul R. Bergin \\ Giancarlo Corsetti \\ Working Paper 25765 \\ http://www.nber.org/papers/w25765
NATIONAL BUREAU OF ECONOMIC RESEARCH
1050 Massachusetts Avenue
Cambridge, MA 02138
April 2019

We thank our discussants Matteo Cacciatore, Fabio Ghironi, Paolo Pesenti, and Hélène Rey, as well as Mary Amiti, Giovanni Maggi, Sam Kortum, Kim Ruhl, and seminar participants at the 2013 NBER Summer Institute, the International Finance and Macro Finance Workshop at Sciences Po Paris, the Norges Bank Conference The Role of Monetary Policy Revisited, the 2016 ASSA meetings, the West Coast Workshop on International Finance and Open Economy Macroeconomics, the CPBS Pacific Basin Research Conference, the Banque de France PSE Trade Elasticities Workshop, Bank of England, Bank of Spain, London Business School, New York FED the National University of Singapore, Universidade Nova de Lisboa, and the Universities of Cambridge, Wisconsin, and Yale for comments. Yuan Liu, Riccardo Trezzi and Jasmine Xiao provided excellent research assistance. Giancarlo Corsetti acknowledges the generous support of the Keynes Fellowship at Cambridge University, the Cambridge Inet Institute and Centre for Macroeconomics. Finally, we thank Giovanni Lombardo for generous and invaluable technical advice. The views expressed herein are those of the authors and do not necessarily reflect the views of the National Bureau of Economic Research.

NBER working papers are circulated for discussion and comment purposes. They have not been peerreviewed or been subject to the review by the NBER Board of Directors that accompanies official NBER publications.

(C) 2019 by Paul R. Bergin and Giancarlo Corsetti. All rights reserved. Short sections of text, not to exceed two paragraphs, may be quoted without explicit permission provided that full credit, including (c) notice, is given to the source. 
Beyond Competitive Devaluations: The Monetary Dimensions of Comparative Advantage Paul R. Bergin and Giancarlo Corsetti

NBER Working Paper No. 25765

April 2019

JEL No. F41

\begin{abstract}
$\underline{\text { ABSTRACT }}$
Motivated by the long-standing debate on the pros and cons of competitive devaluation, we propose a new perspective on how monetary and exchange rate policies can contribute to a country's international competitiveness. We refocus the analysis on the implications of monetary stabilization for a country's comparative advantage. We develop a two-country New-Keynesian model allowing for sectoral differences in the production of tradables in each economy: while in one sector firms are perfectly competitive, in another sector firms produce differentiated goods under monopolistic competition and subject to nominal rigidities, hence their performance is more sensitive to macroeconomic uncertainty. We show that, by stabilizing inflation and the output gap, monetary policy can foster the competitiveness of these firms, encouraging investment and entry in the differentiated goods sector, and ultimately affecting the composition of domestic output and exports. Welfare implications of alternative monetary policy rules that shift comparative advantage are found to be substantial in a calibrated version of the model.
\end{abstract}

\author{
Paul R. Bergin \\ Department of Economics \\ University of California, Davis \\ One Shields Ave. \\ Davis, CA 95616 \\ and NBER \\ prbergin@ucdavis.edu \\ Giancarlo Corsetti \\ Faculty of Economics \\ Cambridge University \\ Sidgwick Avenue \\ CB3 9DD Cambridge, Cambs \\ United Kingdom \\ giancarlo.corsetti@gmail.com
}

A data appendix is available at http://www.nber.org/data-appendix/w25765 


\section{Introduction}

This paper offers a new perspective on how monetary and exchange rate policy can strengthen a country's international competitiveness. Conventional policy models emphasize the competitive gains from currency devaluation, which lowers the relative cost of producing in a country over the time span that domestic wages and prices remain sticky. In modern monetary theory and central bank practice, however, reliance on devaluation to boost competitiveness is not viewed as a viable policy recommendation on two accounts. First, it may be interpreted as a strategic beggar-thy-neighbor measure, inviting retaliation up to causing currency wars, and second, because of its discretionary nature, it is expected to worsen the short-run trade-offs between inflation and unemployment. The New Open Economy Macro (NOEM) and New-Keynesian (NK) literature has indeed moved away from the conventional policy model, stressing that monetary policymakers can exploit a country's monopoly on its terms of trade. As this typically means pursuing a higher international price of home goods, however, desirable policy measures seem to go in the opposite direction relative to improving competitiveness. ${ }^{1}$ In this paper, we take an altogether different perspective, and explore the relevance for a country's comparative advantage of adopting monetary and exchange rate regimes which may or may not deliver efficient macroeconomic stabilization.

We motivate our analysis with the observation that monetary policy aimed at stabilizing marginal costs and demand conditions at an aggregate level (weakening or strengthening the exchange rate in response to cyclical disturbances) is likely to have asymmetric effects across sectors. Stabilization policy can be expected to be more consequential in industries where firms face significant nominal rigidities and incur significant up-front investment to enter the market - features typically associated with differentiated manufacturing goods. To the extent that monetary policy ensures domestic macroeconomic stability, it creates favorable conditions for firms' entry in such industries,

\footnotetext{
${ }^{1}$ The new-open economy macroeconomics and New-Keynesian literature emphasize a trade-off between output gap, defined as the difference between equilibrium output in the model with distortions and its firstbest level in a world without distortions, and exchange rate stabilization due to a terms-of-trade externality, similar to that underlying the optimal tariff argument. For example, see Obstfeld and Rogoff (2000), Corsetti and Pesenti (2001, 2005), and Canzoneri et al. (2005) in the NOEM literature, as well as Benigno and Benigno (2003) and Corsetti et al. (2010) in the New-Keynesian literature, among others. Provided the demand for exports and imports is relatively elastic, an appreciation of the terms of trade of manufacturing allows consumers to substitute imports for domestic goods, reducing the disutility of labor without appreciable effects on the marginal utility of consumption.
} 
with potentially long-lasting effects on their competitiveness, and thus on the weight of their production in domestic output and exports.

To illustrate our new perspective on the subject, we specify a stochastic generalequilibrium monetary model of open economies with incomplete specialization across two tradable sectors. In one sector, firms produce an endogenous set of differentiated varieties operating under imperfect competition; in the other sector, firms produce highly substitutable, non-differentiated goods - for simplicity we assume perfect competition. The key distinction between these sectors is that differentiated goods producers face a combination of nominal rigidities and sunk entry costs that make them more sensitive to macroeconomic uncertainty.

The key result from our model is that efficient stabilization regimes affect the average relative price of a country's differentiated goods in terms of its non-differentiated goods, and, relative to the case of insufficient stabilization, confer comparative advantage in the sale of differentiated goods both at home and abroad. Underlying this result is a transmission channel at the core of modern monetary literature: in the presence of nominal rigidities, uncertainty implies the analog of a risk premium in a firm's optimal prices, depending on the covariance of demand and marginal costs (See Obstfeld and Rogoff 2000, Corsetti and Pesenti 2005, and Fernandez-Villaverde et al. 2011). We show that, by impinging on this covariance, and thus on the variability of the ex-post markups, optimal monetary policy contributes to manufacturing firms setting prices that, on average, are efficiently low and competitive, with a positive demand externality affecting the size of the market. A large market in turn strengthens the incentive for new manufacturing firms to enter, see e.g., Bergin and Corsetti (2008) and Bilbiie, Ghironi and Melitz (2008). An implication of the theory that is relevant for policy-related research is that, everything else equal, countries with a reduced ability to stabilize macro shocks will tend to specialize away from differentiated manufacturing goods, relative to the countries that use their independent monetary policy to pursue inflation and output gap stabilization.

The effect of monetary policy on the composition of output and exports has a key implication for the terms of trade of the country. Comparative advantage in manufacturing means that, thanks to better stabilization, the country can sell its differentiated goods at a competitive, hence lower, price in the global market. However, the fact that it sells more manufacturing goods, and imports more non-differentiated goods, means that, overall, the terms of trade of the country improve. The importance of this result should not be missed. 
It shows that one of the key tenets of the New-Keynesian model, concerning the relevance of improved terms of trade for the conduct of monetary policy, does not necessarily require monetary policy to hamper firms' price competitiveness, as is the case if the model specification is restricted to include only one-tradable good. In this respect, our generalization of the model, closer to trade theory, provides a new perspective and new foundation to the extant literature.

Numerical simulations are conducted on a calibrated version of the model, including TFP shocks calibrated to novel estimates of the TFP process for differentiated and non-differentiated sectors in the U.S. As a baseline, we characterize the Ramsey optimal policy allocation and show that, in terms of welfare levels, the same outcome can be supported by policy rules that fully stabilize inflation and output gaps in each country. Relative to the Ramsey baseline, our key result is that, when one country replaces the optimal stabilization rule with a unilateral exchange rate peg (implying insufficient inflation and output gap stabilization), the new regime substantially shifts comparative advantage. The country pursuing the peg loses out production and exports of differentiated goods to the country that maintains an efficient stabilization regime. In particular, compared to the symmetric Ramsey solution, the share of exports in differentiated goods falls by 4.5 percentage points in the country pursuing a peg; it rises by a similar amount in the country that keeps its inflation stabilization policy. Associated with this relocation of exports and production across countries is a substantial shift in firm entry: the pegger experiences a $7 \%$ drop in the number of firms in the differentiated goods sector, corresponding to a rise in the stabilizing country. Due to the drop in firm entry, the pegging country thus accounts for a smaller share of the range of varieties of differentiated goods available to consumers in both countries.

The shift in comparative advantage and production relocation have substantial welfare implications at the country level. In our calibration, welfare of the pegging country falls $1.8 \%$ relative to the Ramsey policy, and the welfare of the stabilizing country rises above the Ramsey policy by $1.4 \%$. These effects are large by the standards of the monetary policy literature, but are essentially redistributive: one country's loss is another country's gain, with overall modest implications for global aggregate welfare. Underlying this result are the welfare gains in terms of reduced trade costs, from relocating production of differentiated goods to the domestic economy, as discussed by trade literature on the Home Market Effect and the production relocation externality (see Ossa, 2011). Our contribution is 
to show how this externality is relevant not only for trade policy, but also to stabilization policy - the more so, the higher the demand and productivity uncertainty faced by firms.

In this respect, we should stress two key features of our model that are essential to derive our main results. The first is the possibility of shifting comparative advantage between two tradable sectors, a novel feature in monetary economics. A model specification with either one tradable goods sector only, or with one tradable and one nontradable sector would not deliver this result. In either specification, each country has a set comparative advantage in its own tradable by construction, and, trivially, there can be no change in the composition of the bundle of exports in response to fundamental shocks and policy. The second is firms' entry affecting the bundle of goods varieties produced by a country, and hence potential gains from saving on trade costs. Versions of the model that exogenously hold constant the number of firms in each country mute the quantitative effects of asymmetric stabilization policy on production, exports and welfare.

Our paper is related to a large open economy macro literature studying optimal exchange rate and macroeconomic stabilization policy. Our specific contribution consists of studying the extent to, and the mechanisms by which, this policy affects endogenous specialization among multiple traded sectors. As discussed above, we differ from the vast majority of the macro literature in that we relax the assumption of one traded goods sector only. Even among the small set of papers that, like us, specify economies with more than one traded sector, we found no other that allows for endogenous comparative advantage. For example, Lombardo and Ravenna (2014) allow for imports of both intermediates and final goods, yet they assume that only final goods are exportable. As a result, they can analyze how the design of optimal stabilization policy depends on an exogenously given composition of trade, but not how this composition of trade may depend on policy.

Two tradable sectors are of course standard in the set of open economy and monetary models focusing on oil price shocks. In many contributions a tradable commodity sector coexists with a sticky price differentiated goods sector. However, obvious differences relative to our work preclude this literature from studying the comparative advantage and production relocation driving our results. Bodenstein et al. (2012) simplifies the supply side of the oil sector by assuming an exogenous endowment, which is reasonable for studying the oil market, but rules out endogenous specialization. Nakov and Pescatori $(2010 \mathrm{a}, \mathrm{b})$ endogenize the production of oil, but assume a dominant oil exporter 
(OPEC) that exogenously specializes and exports from the oil sector, again ruling out the effect of monetary policy on endogenous specialization.

From the perspective of trade theory, our analysis is related to work on tariffs by Ossa (2011), which nonetheless abstracts from nominal rigidities and other distortions that motivate our focus on stabilization policy. Ossa's paper, like ours, models a country's comparative advantage drawing on the literature dealing with the 'home market effect' after Krugman (1980), implying production relocation externalities associated with the expansion of manufacturing. ${ }^{2}$ This relationship also applies to recent work by Epifani and Gancia (2017), who revisit the 'transfer problem' of trade in the context of production relocation externalities; again, they do not study monetary policy or consider an environment with nominal rigidities.

Our work is also related to the trade literature studying how various institutions and policies, such as labor market regulation or legal frameworks, affect comparative advantage between multiple traded sectors. Cunat and Melitz (2012) and Nunn (2007) are two examples. With respect to this international trade literature, our paper's novel contribution is to posit that the conduct of monetary policy is another, previously unstudied, institutional feature that should be added to the list of those that affect comparative advantage.

Finally, we note that the mechanisms by which monetary policy may influence comparative advantage are of course relevant also for stabilization policies relying on fiscal and financial instruments. Taxes and subsidies may contribute to demand and markup stabilization, containing the distortions due to nominal price stickiness and thus, according to our core argument, misallocation across sectors. While, everything else equal, inefficient monetary stabilization (e.g., deriving from adopting a fixed exchange) may hamper comparative advantage in manufacturing, substitution among policy instruments may make up for constraints on monetary policy. Our analysis shows a specific reason why exploiting a wide range of stabilization instruments is particularly valuable.

\footnotetext{
${ }^{2}$ According to the literature stressing the 'home market effect,' the social benefits from gaining comparative advantage in the manufacturing sector stem from a 'production relocation externality:' acquiring a larger share of the world production of differentiated goods generates welfare gains due to savings on trade costs. Our work is also related to Corsetti et al. (2007), which considers the role of the home market effect in a real trade model, as well as Ghironi and Melitz (2005). We differ from the latter in that we model two tradable sectors, and study the implications of monetary policy for comparative advantage.
} 
The text is structured as follows. The next section describes the model. Section 3 develops intuition by deriving analytical results for a simplified version of the model. Section 4 uses stochastic simulations to demonstrate a broader set of implications. Sections 5 and 6 delve into extensive sensitivity analysis to explore the core mechanism underlying our results, and check their robustness. Section 7 concludes.

\section{An open economy model with comparative advantage across two tradable sectors}

In what follows, we develop a two-country monetary model, introducing a key novel element in the way we specify the goods market structure. Namely, the home and foreign countries each produce two types of tradable goods. The first type comes in differentiated varieties produced under monopolistic competition. Firms in this sector face a sunk investment cost to enter the market with a new variety, and set prices subject to nominal rigidities; moreover, production may require intermediates in a round-about production structure. The second type of good is modeled according to the standard specification in real business cycle models. For this good, there is perfect substitutability among producers within a country (indeed, the good is produced under perfect competition), but imperfect substitutability across countries, as summarized by an Armington elasticity.

In the text to follow, we present the households' and firms' problems as well as the monetary and fiscal policy rules from the vantage point of the home economy, with the understanding that similar expressions and considerations apply to the foreign economyforeign variables are denoted with a “*”.

\subsection{Goods consumption demand and price indexes}

Households consume goods produced in both sectors, of domestic and foreign origin. The differentiated goods come in many varieties, produced by a time-varying number of monopolistically competitive firms in the home and foreign country, $n_{t}$ and $n_{t}{ }^{*}$ respectively, each producing a single variety. Each variety is an imperfect substitute for any other variety in this sector, either of home or foreign origin, with elasticity $\phi$. The nondifferentiated goods come in a home and foreign version, which are imperfect substitutes with elasticity $\eta$. However, within each country, all goods in this sector are perfectly substitutable with each other, and are produced in a perfectly competitive environment. We will refer to the differentiated sector as "manufacturing," and denote this sector with a 
$D$; we will denote the non-differentiated sector with a $N$.

The overall consumption index is specified as follows:

$$
C_{t} \equiv C_{D, t}^{\theta} C_{N, t}^{1-\theta},
$$

where

$$
C_{D, t} \equiv\left(\int_{0}^{n_{t}} c_{t}(h)^{\frac{\phi-1}{\phi}} d h+\int_{0}^{n_{t}^{*}} c_{t}(f)^{\frac{\phi-1}{\phi}} d f\right)^{\frac{\phi}{\phi-1}}
$$

is the index over the endogenous number of home and foreign varieties of the differentiated manufacturing good, $c_{t}(h)$ and $c_{t}(f)$, and

$$
C_{N, t} \equiv\left(v^{\frac{1}{\eta}} C_{H, t}^{\frac{\eta-1}{\eta}}+(1-v)^{\frac{1}{\eta}} C_{F, t}^{\frac{\eta-1}{\eta}}\right)^{\frac{\eta}{\eta-1}}
$$

is the index over goods differentiated only by country of origin, $C_{H, t}$ and $C_{F, t}$ with $v \in[0,1]$ accounting for the weight on domestic goods. For clarity, Figure 1 illustrates the aggregation of goods for consumption. The corresponding welfare-based consumption price index is

$$
P_{t} \equiv \frac{P_{D, t}^{\theta} P_{N, t}^{1-\theta}}{\theta^{\theta}(1-\theta)^{1-\theta}},
$$

where

$$
P_{D, t}=\left(n_{t} p_{t}(h)^{1-\phi}+n_{t}^{*} p_{t}(f)^{1-\phi}\right)^{\frac{1}{1-\phi}}
$$

is the index over the prices of all varieties of home and foreign manufacturing goods, $p_{t}(h)$ and $p_{t}(f)$, and

$$
P_{N, t}=\left(v P_{H, t}{ }^{1-\eta}+(1-v) P_{F, t}{ }^{1-\eta}\right)^{\frac{1}{1-\eta}}
$$

is the index over the prices of home and foreign non-differentiated goods.

The relative demand functions for domestic residents implied from our specification of preferences are listed below:

$$
\begin{array}{ll}
C_{D, t}=\theta P_{t} C_{t} / P_{D, t} & C_{N, t}=(1-\theta) P_{t} C_{t} / P_{N, t} \\
C_{t}(h)=\left(p_{t}(h) / P_{D, t}\right)^{-\phi} C_{D, t} & C_{t}(f)=\left(p_{t}(f) / P_{D, t}\right)^{-\phi} C_{D, t} \\
C_{H, t}=v\left(P_{H, t} / P_{N, t}\right)^{-\eta} C_{N, t} & C_{F, t}=(1-v)\left(P_{F, t} / P_{N, t}\right)^{-\eta} C_{N, t}
\end{array}
$$




\subsection{Home households' problem}

The representative home household derives utility from consumption $\left(C_{t}\right)$, and from holding real money balances $\left(M_{t} / P_{t}\right)$; it suffers disutility from labor $\left(l_{t}\right)$. The household budget consists of labor income from working at the nominal wage rate $W_{t}$; profits rebated from home firms denoted with $\left(\Pi_{t}\right)$ in real terms and defined below, as well as interest income on bonds in home currency $\left(i_{t-1} B_{H, t-1}\right)$ and foreign currency $\left(i_{t-1}{ }^{*} B_{F, t-1}\right)$, where $e_{t}$ is the nominal exchange rate in units of home currency per foreign. Income is net of lumpsum taxes $\left(T_{t}\right)$.

Household optimization for the home country may be written:

$$
\max E_{0} \sum_{t=0}^{\infty} \beta^{t} U\left(C_{t}, l_{t}, \frac{M_{t}}{P_{t}}\right)
$$

where utility is defined by

$$
U_{t}=\frac{1}{1-\sigma} C_{t}^{1-\sigma}+\ln \frac{M_{t}}{P_{t}}-\frac{1}{1+\psi} l_{t}^{1+\psi}
$$

subject to the budget constraint:

$$
P_{t} C_{t}+\left(M_{t}-M_{t-1}\right)+\left(B_{H t}-B_{H t-1}\right)+e_{t}\left(B_{F t}-B_{F t-1}\right)=W_{t} l_{t}+\Pi_{t}+i_{t-1} B_{H t-1}+i_{t-1}^{*} B_{F t-1}-P_{t} A C_{B t}-T_{t} .
$$

In the utility function, the parameter $\sigma$ denotes risk aversion and $\psi$ is the inverse of the Frisch elasticity. The constraint includes a small cost to holding foreign bonds

$$
A C_{B t}=\frac{\psi_{B}\left(e_{t} B_{F t}\right)^{2}}{2 P_{t} p_{H t} y_{H t}},
$$

scaled by $\psi_{\mathrm{B}}$, which is a common device to assure long run stationarity in the net foreign asset position, and resolve indeterminacy in the composition of the home bond portfolio. The bond adjustment cost is a composite of goods that mirrors the consumption index, with analogous demand conditions to equation (4)-(9). ${ }^{3}$

Defining $\mu_{t}=P_{t} C_{t}^{\sigma}$, household optimization implies an intertemporal Euler equation:

$$
\frac{1}{\mu_{t}}=\beta\left(1+i_{t}\right) E_{t}\left[\frac{1}{\mu_{t+1}}\right]
$$

a labor supply condition:

\footnotetext{
${ }^{3}$ See the appendix for the full set of demand equations. Note that the different components of aggregate demand fall on different baskets of final goods, e.g., intermediate inputs and sunk entry costs only involve goods from the differentiated goods sector. Nonetheless, the demand for differentiated goods follows on the same CES basket, defined over available varieties with the same elasticity of substitution.
} 


$$
W_{t}=l_{t}^{\psi} \mu_{t}
$$

a money demand condition:

$$
M_{t}=\mu_{t}\left(\frac{1+i_{t}}{i_{t}}\right)
$$

and a home interest rate parity condition:

$$
\mathrm{E}_{\mathrm{t}}\left[\frac{\mu_{\mathrm{t}}}{\mu_{\mathrm{t}+1}} \frac{e_{\mathrm{t}+1}}{e_{\mathrm{t}}}\left(1+\mathrm{i}_{\mathrm{t}}^{*}\right)\left(1+\psi_{\mathrm{B}}\left(\frac{e_{t} B_{f t}}{p_{H t} y_{H t}}\right)\right)\right]=\mathrm{E}_{\mathrm{t}}\left[\frac{\mu_{\mathrm{t}}}{\mu_{\mathrm{t}+1}}\left(1+\mathrm{i}_{\mathrm{t}}\right)\right] .
$$

The problem and first order conditions for the foreign household are analogous.

\subsection{Home firm problem and entry condition in the differentiated goods sector}

In the manufacturing sector, the production of each differentiated variety follows

$$
y_{t}(h)=\alpha_{D, t}\left[G_{t}(h)\right]^{\zeta}\left[l_{t}(h)\right]^{1-\zeta},
$$

where $\alpha_{D, t}$ is a productivity shock specific to the production of differentiated goods but common to all firms within that sector, $l_{t}(h)$ is the labor employed by firm $h$, and $G_{t}(h)$ is a composite of differentiated goods used by firm $h$ as an intermediate input. $G_{t}(h)$ is specified as an index of home and foreign differentiated varieties that mirrors the consumption index specific to differentiated goods $\left(C_{D, t}\right)$. If we sum across firms, $G_{t}=n_{t} G_{t}(h)$ represents economy-wide demand for differentiated goods as intermediate inputs, and given that the index is the same as for consumption, this implies demands for differentiated goods varieties analogous to equations (6)-(7).

$$
d_{G, t}(h)=\left(p_{t}(h) / P_{D, t}\right)^{-\phi} G_{t} \quad d_{G, t}(f)=\left(p_{t}(f) / P_{D, t}\right)^{-\phi} G_{t}
$$

Differentiated goods firms set prices $p_{t}(h)$ subject to an adjustment cost:

$$
A C_{P, t}(h)=\frac{\psi_{P}}{2}\left(\frac{p_{t}(h)}{p_{t-1}(h)}-1\right)^{2} \frac{p_{t}(h) y_{t}(h)}{P_{t}},
$$

where $\psi_{P}$ is a calibrated parameter governing the degree of price stickiness. For the sake of tractability, we follow Bilbiie et al. (2008) in assuming that new entrants inherit from the price history of incumbents the same price adjustment cost, and so make the same price setting decision. ${ }^{4}$

\footnotetext{
${ }^{4}$ The price index for adjustment cost is identical to the overall consumption price index, implying demands analogous to those for consumption in equations (4)-(9). See the supplementary online appendix for the full list of equations.
} 
There is free entry in the sector, but, once active, firms are subject to an exogenous death shock. Since all differentiated goods producers operating at any given time face the same exogenous probability of exit $\delta$, a fraction $\delta$ of them exogenously stop operating each period. The number of firms active in the differentiated sector, $n_{t}$, at the beginning of each period evolves according to:

$$
n_{t+1}=(1-\delta)\left(n_{t}+n e_{t}\right)
$$

where $n e_{t}$ denotes new entrants.

To set up a firm, managers incur a one-time sunk cost, $K_{t}$, and production starts with a one-period lag. This cost is not constant but varies reflecting an entry congestion externality, represented as an adjustment cost that is a function of the number of new firms:

$$
K_{t}=\left(\frac{n e_{t}}{n e_{t-1}}\right)^{\lambda} \bar{K},
$$

where $\bar{K}$ indicates the steady state level of entry cost, and the parameter $\lambda$ indicates how much the entry cost rises with an increase in entry activity. The congestion externality plays a similar role as the adjustment cost for capital standard in business cycle models, which moderates the response of investment to match dynamics in data. In a similar vein, we calibrate the adjustment cost parameter, $\lambda$, to match data on the dynamics of new firm entry. ${ }^{5}$ Entry costs are specified either in units of labor (if $\theta_{K}=1$ ) or in units of the differentiated good (if $\theta_{K}=0$ ). If entry costs are in units of differentiated goods, the investment-driven demand is distributed analogously to demands for consumption of differentiated goods:

$$
\begin{gathered}
d_{K, t}(h)=\left(p_{t}(h) / P_{D, t}\right)^{-\phi} n e_{t}\left(1-\theta_{K}\right) K_{t} \\
d_{K, t}(f)=\left(p_{t}(f) / P_{D, t}\right)^{-\phi} n e_{t}\left(1-\theta_{K}\right) K_{t} .
\end{gathered}
$$

We now can specify total demand facing a domestic differentiated goods firm:

$$
d_{t}(h)=c_{t}(h)+d_{G, t}(h)+d_{K, t}(h)+d_{A C, P, t}(h)+d_{A C, B, t}(h)
$$

which includes the demand for consumption $\left(c_{t}(h)\right)$ by households, and the demand by firms for intermediate inputs $\left(d_{G, t}(h)\right)$, investment (the sunk entry costs) $\left(d_{K, t}(h)\right)$, and goods absorbed as adjustment costs for prices $\left(d_{A C, P, t}(h)\right)$ and bonds holding costs

\footnotetext{
${ }^{5}$ The value of steady state entry cost $\bar{K}$ has no effect on the dynamics of the model, and so will be normalized to unity.
} 
$\left(d_{A C, B, t}(h)\right)$. There is an analogous demand from abroad $d_{t}^{*}(h)$. We assume iceberg trade $\operatorname{costs} \tau_{D}$ for exports, so that market clearing for a firm's variety is:

$$
y_{t}(h)=d_{t}(h)+\left(1+\tau_{D}\right) d_{t}^{*}(h),
$$

Firm profits are computed as:

$$
\pi_{t}(h)=p_{t}(h) d_{t}(h)+e_{t} p_{t}^{*}(h) d_{t}^{*}(h)-m c_{t} y_{t}(h)-P_{t} A C_{p, t}(h) .
$$

where $m c_{t}=\zeta^{-\zeta}(1-\zeta)^{\zeta-1} P_{D, t}^{\zeta} W_{t}^{1-\zeta} / \alpha_{D, t}$ is marginal cost.

Thus the value function of firms that enter the market in period $t$ may be represented as the discounted sum of profits of domestic sales and export sales:

$$
v_{t}(h)=E_{t}\left\{\sum_{s=0}^{\infty}(\beta(1-\delta))^{s} \frac{\mu_{t+s}}{\mu_{t}} \pi_{t+s}(h)\right\},
$$

where we assume firms use the discount factor of the representative household, who owns the firm, to value future profits. With free entry, new producers will invest until the point that a firm's value equals the entry sunk cost:

$$
v_{t}(h)=\left(\theta_{K} W_{t}+\left(1-\theta_{K}\right) P_{D, t}\right) K_{t},
$$

recalling $\theta_{K}=1$ is the case of entry costs in labor units, and $\theta_{K}=0$ the case of goods units. By solving for cost minimization we can express the relative demand for labor and intermediates as a function of their relative costs:

$$
\frac{P_{D, t} G_{t}(h)}{W_{t} l_{t}(h)}=\frac{\zeta}{1-\zeta} .
$$

Managers optimally set prices by maximizing the firm value subject to all the constraints specified above. The price setting equation:

$$
\begin{aligned}
& p_{t}(h)=\frac{\phi}{\phi-1} m c_{t}+\frac{\psi_{P}}{2}\left(\frac{p_{t}(h)}{p_{t-1}(h)}-1\right)^{2} p_{t}(h)-\psi_{P} \frac{1}{\phi-1}\left(\frac{p_{t}(h)}{p_{t-1}(h)}-1\right) \frac{p_{t}(h)^{2}}{p_{t-1}(h)} \\
& +\frac{\psi_{P}}{\phi-1} E_{t}\left[\beta \frac{\Omega_{t+1}}{\Omega_{t}}\left(\frac{p_{t+1}(h)}{p_{t}(h)}-1\right) \frac{p_{t+1}(h)^{2}}{p_{t}(h)}\right]
\end{aligned}
$$

expresses the optimal pricing as a function of the stochastically discounted demand faced by producers of domestic differentiated goods, 


$$
\begin{aligned}
\Omega_{t} & =\left[\left(\frac{p_{t}(h)}{P_{D, t}}\right)^{-\phi}\left(C_{D, t}+G_{t}+n e_{t}\left(1-\theta_{K}\right) K_{t}+A C_{P, D, t}+A C_{B, D, t}\right)\right. \\
& \left.+\left(\frac{\left(1+\tau_{D}\right) p_{t}(h)}{e_{t} P^{*}}\right)^{-\phi}\left(1+\tau_{D}\right)\left(C_{D, t}^{*}+G_{t}^{*}+n e_{t}^{*}\left(1-\theta_{K}\right) K_{t}^{*}+A C_{P, D, t}^{*}+A C_{B, D, t}^{*}\right)\right] / \mu_{t}
\end{aligned}
$$

This sums the demand arising from consumption, use as intermediate inputs, sunk entry cost, price adjustment costs, and bond holding costs.

Under the assumption that firms preset prices in own currency, i.e., assuming producer currency pricing, the good price in foreign currency moves one-to-one with the exchange rate, net of trade costs:

$$
p_{t}^{*}(h)=\left(1+\tau_{D}\right) p_{t}(h) / e_{t}
$$

where recall the nominal exchange rate, $e$, measures home currency units per foreign.

Note that, since households own firms, they receive firm profits but also finance the creation of new firms. In the household budget, the net income from firms may be written:

$$
\Pi_{t}=n_{t} \pi_{t}(h)-n e_{t} v_{t}(h) .
$$

In reporting our quantitative results, we will refer to the overall home gross production of differentiated goods defined as: $y_{D, t}=n_{t} y_{t}(h)$.

\subsection{Home firm problem in the undifferentiated goods sector}

In the second sector firms are assumed to be perfectly competitive in producing a good differentiated only by country of origin. The production function for the home nondifferentiated good is linear in labor:

$$
y_{H, t}=\alpha_{N, t} l_{H, t},
$$

where $\alpha_{N, t}$ is stochastic productivity specific to this country and sector. It follows that the price of the homogeneous goods in the home market is equal to marginal costs:

$$
p_{H, t}=W_{t} / \alpha_{N, t} \cdot
$$

An iceberg trade cost specific to the non-differentiated sector implies prices of the home good abroad are

$$
p_{H, t}^{*}=p_{H, t}\left(1+\tau_{N}\right) / e_{t} .
$$

Analogous conditions apply to the foreign non-differentiated sector. 


\subsection{Monetary policy}

The goal of our analysis is to trace the effects of monetary policy regimes on comparative advantage and the composition of production and exports. Consistent with this goal, we compute the Ramsey allocation as our optimal policy benchmark. Relative to this benchmark, we will study the implications of different types of policies.

To compute the Ramsey allocation, we posit that the monetary authority maximizes aggregate welfare of both countries:

$$
\max E_{0} \sum_{t=0}^{\infty} \beta^{t}\left(\frac{1}{2}\left(\frac{1}{1-\sigma} C_{t}^{1-\sigma}-\frac{1}{1+\psi} l_{t}^{1+\psi}\right)+\frac{1}{2}\left(\frac{1}{1-\sigma} C_{t}^{*_{1}-\sigma}-\frac{1}{1+\psi} l_{t}^{*_{1}+\psi}\right)\right)
$$

under the constraints of the economy defined above. As common in the literature, we write the Ramsey problem by introducing additional co-state variables, which track the value of the planner committing to a policy plan.

We study an inflation targeting regime by positing a rule that fully stabilizes output gaps. In the context of this model, this rule fully stabilizes prices in the differentiated goods sector:

$$
\frac{p_{t}(h)}{p_{t-1}(h)}=1 .
$$

As will be discussed below, targeting inflation specific to the differentiated goods sector is sufficient to replicate the flexible price equilibrium. To study a policy that deviates substantially from optimal stabilization, we posit that a country renounces monetary independence, and pursues a peg of the nominal exchange rate,

$$
\frac{e_{t}}{e_{t-1}}=1
$$

Enforcement of this peg may be assigned either to the home or foreign policy maker.

For comparing the model to data, we approximate historical policy rules with the following Taylor rule:

$$
1+i_{t}=\left(1+i_{t-1}\right)^{\gamma_{i}}\left[(1+\bar{i})\left(\frac{p_{t}(h)}{p_{t-1}(h)}\right)^{\gamma_{p}}\left(\frac{Y_{t}}{\bar{Y}}\right)^{\gamma_{Y}}\right]^{1-\gamma_{i}},
$$

where terms with overbars are steady state values. In this rule, inflation is defined in terms of differentiated goods producer prices, while $Y_{t}$ is a measure of GDP defined net of intermediates as: ${ }^{6}$

\footnotetext{
${ }^{6}$ For computational simplicity, the Taylor rule is specified in terms of deviations of GDP from its steady state value, which is distinct from the output gap.
} 


$$
Y_{t}=\left(\left(1+n_{t}\right)^{(-1 /(1-\sigma))} \int_{0}^{n_{t}} p_{t}(h) y_{t}(h) d h-P_{D, t} G_{t}+p_{H, t} y_{H, t}\right) / P_{t} .
$$

Across these different specifications of monetary policy, we will abstract from public consumption expenditure, so that the government uses seigniorage revenues and taxes to finance transfers, assumed to be lump sum. The home government faces the budget constraint:

$$
M_{t}-M_{t-1}+T_{t}=0
$$

\subsection{Market clearing}

The market clearing condition for the manufacturing goods market is given in equation (22) above. Market clearing for the non-differentiated goods market requires:

$$
\begin{aligned}
& y_{H, t}=C_{H, t}+A C_{P, H, t}+A C_{B, H, t}+\left(1+\tau_{N}\right)\left(C_{H, t}^{*}+A C_{P, H, t}^{*}+A C_{B, H, t}^{*}\right) \\
& y_{F, t}=\left(1+\tau_{N}^{*}\right)\left(C_{F, t}+A C_{P, F, t}+A C_{B, F, t}\right)+C_{F, t}^{*}+A C_{P, F, t}^{*}+A C_{B, F, t}^{*} .
\end{aligned}
$$

Labor market clearing requires:

$$
\int_{0}^{n_{t}} l_{t}(h) d h+l_{H, t}+\theta_{K} n e_{t} K_{t}=l_{t}
$$

Bond market clearing requires:

$$
\begin{aligned}
& B_{H t}+B_{H t}^{*}=0 \\
& B_{F t}+B_{F t}^{*}=0 .
\end{aligned}
$$

Balance of payments requires:

$$
\begin{aligned}
& \int_{0}^{n_{t}} p_{t}^{*}(h)\left(d_{t}^{*}(h)\right) d h-\int_{0}^{n_{t}^{*}} p_{t}(f)\left(d_{t}(f)\right) d f+P_{H t}^{*}\left(C_{H, t}^{*}+A C_{P, H, t}^{*}+A C_{B, H, t}^{*}\right) \\
& -P_{F, t}\left(C_{F, t}+A C_{P, F, t}+A C_{B, F, t}\right)-i_{t-1} B_{H, t-1}^{*}+e_{t}^{*} i_{t-1}^{*} B_{F, t-1}=\left(B_{H, t}^{*}-B_{H, t-1}^{*}\right)+e_{t}\left(B_{F, t}-B_{F, t-1}\right) .
\end{aligned}
$$

\subsection{Shocks process and equilibrium definition}

We will consider a number of shocks studied in the literature, featuring shocks to productivity, but also including shocks to intertemporal consumption preferences, money demand, and fiscal policy. Given the structure of our economy, shocks are assumed to follow joint log normal distributions. In the case of productivity, for instance, we can write: 


$$
\left[\begin{array}{l}
\log \alpha_{D, t}-\log \overline{\alpha_{D}} \\
\log \alpha_{N, t}-\log \overline{\alpha_{N}}
\end{array}\right]=\rho\left[\begin{array}{l}
\log \alpha_{D, t-1}-\log \overline{\alpha_{D}} \\
\log \alpha_{N, t-1}-\log \overline{\alpha_{N}}
\end{array}\right]+\varepsilon_{t}
$$

with autoregressive coefficient matrix $\rho$, and the covariance matrix $E\left[\varepsilon_{t} \varepsilon_{t}^{\prime}\right]$.

A competitive equilibrium in our world economy is defined along the usual lines, as a set of processes for quantities and prices in the home and foreign country satisfying: (i) the household and firms optimality conditions; (ii) the market clearing conditions for each good and asset, including money; (iii) the resource constraints-whose specification can be easily derived from the above and is omitted to save space.

\subsection{Relative price and export share measures}

Along with the real exchange rate $\left(e_{t} P_{t}^{*} / P_{t}\right)$, we report two alternative measures of international prices. First, as is common practice in the production of statistics on international relative prices, we compute the terms of trade weighting goods with their respective expenditure shares:

$$
\operatorname{TOTS}_{t} \equiv \frac{\omega_{H t} p_{t}(h)+\left(1-\omega_{H t}\right) p_{H, t}}{\omega_{F t} e_{t} p_{t}^{*}(f)+\left(1-\omega_{F t}\right) e_{t} p_{F, t}^{*}},
$$

where the weight $\omega_{H t}$ measures the share of differentiated goods in the home country's overall exports:

$$
\omega_{H t} \equiv \frac{n_{t} p_{t}^{*}(h) d_{t}^{*}(h)}{n_{t} p_{t}^{*}(h) d_{t}^{*}(h)+P_{H, t}^{*}\left(C_{H, t}^{*}+A C_{P, H, t}^{*}+A C_{B, H, t}^{*}\right)},
$$

and $\omega_{F t}$ measures the counterpart for the foreign country:

$$
\omega_{F t} \equiv \frac{n_{t}^{*} p_{t}(f) d_{t}(f)}{n_{t}^{*} p_{t}(f) d_{t}(f)+P_{F t}\left(C_{F, t}+A C_{P, F, t}+A C_{B, F, t}\right)} .
$$

Following the trade literature, we also compute the terms of trade as the ratio of ex-factory prices set by home firms relative to foreign firms in the manufacturing sector:

TOTM $M_{t} \equiv p_{t}(h) /\left(e_{t} p_{t}^{*}(f)\right) .^{7}$ The latter measure ignores the non-differentiated goods sector.

\footnotetext{
${ }^{7}$ This is the same definition used in Ossa (2011). See also Helpman and Krugman (1989), and Campolmi et al. (2014).
} 


\section{Analytical insights from a simplified version of the model}

In this section, we provide a detailed analysis of the mechanism by which monetary policy impinges on pricing by differentiated goods manufactures, ultimately determining the country's comparative advantage in the sector. To be as clear as possible, we work out a simplified version of the model that is amenable to analytical results. Despite a number of assumptions needed to make the model tractable, the key predictions of the simplified model will be confirmed in the full-fledged version of the model.

We specialize our model as follows. First, we posit that production of differentiated goods involves only labor with no intermediates $(\zeta=0)$ and that entry costs are in labor units $\left(\theta_{K}=1\right)$. Second, we consider the case where these differentiated goods firms operate for one period only (implying $\delta=1$ in the entry condition), and symmetrically preset prices over the same horizon. Third, we simplify the non-differentiated good by setting its trade costs to zero $\left(\tau_{N}=0\right)$ and let the elasticity of substitution between home and foreign goods approach infinity $(\eta \rightarrow \infty)$. This implies that the sector produces a homogeneous good, an assumption frequently made in the trade literature. ${ }^{8}$ Fourth, we restrict productivity shocks to be i.i.d., and only occur in the differentiated goods sector (we abstract from productivity shocks in the non-differentiated goods sector). Fifth, utility is $\log$ in consumption and linear in leisure $(\psi=0)$. Finally, we abstract from international asset trade $\left(B_{H}=B_{F}=0\right)$. This simplification has no effect on our results, as we show below that under trade in a single homogenous good whose production is not subject to shocks, production risk is efficiently shared between countries, even in the absence of trade in financial assets, and independently of the way production and trade are specified in the other sector. Drawing on the NOEM literature (see Corsetti and Pesenti 2005, and Bergin and Corsetti 2008), we carry out our analysis of stabilization policy by identifying a country's monetary stance with $\mu_{t}=P_{t} C_{t}$, under the control of monetary authorities via their ability to set the interest rate. Following this approach, we therefore study monetary policy in terms of $\mu_{t}$ (and $\mu_{t}^{*}$ for the foreign country).

In the simplified version of our model, the firms' problem becomes

$$
\max _{p_{t+1}(h)}=E_{t}\left[\beta \frac{\mu_{t}}{\mu_{t+1}} \pi_{t+1}(h)\right],
$$

\footnotetext{
${ }^{8}$ Different from the trade literature, however, we do treat this sector as an integral part of the equilibrium allocation, e.g., exports/imports of the homogeneous good sector enters the terms of trade of the country.
} 
where we have used the fact that the discount rate for nominal quantities coincides with the (inverse of the) growth rate of $\mu_{t}=P_{t} C_{t}$. The optimal preset price in the domestic market is:

$$
p_{t+1}(h)=\frac{\phi}{\phi-1} \frac{E_{t}\left[\Omega_{t+1}\left(\frac{W_{t+1}}{\alpha_{t+1}}\right)\right]}{E_{t}\left[\Omega_{t+1}\right]},
$$

where $W_{t+1} / \alpha_{t+1}=\mu_{t+1} / \alpha_{t+1}$ is the firm's marginal costs, that is, the ratio of nominal wages to labor productivity, and $\Omega_{t+1}$ is the stochastically discounted value of future demand facing the firm for its good in both the domestic and the foreign markets:

$$
\Omega_{t+1}=\left(c_{t+1}(h)+(1+\tau) c_{t+1}^{*}(h)\right) / \mu_{t+1} \cdot{ }^{9}
$$

The home entry condition is a function of price setting and the exchange rate:

$$
\frac{K_{t}}{\beta \theta}=E_{t}\left[\left(p_{t+1}(h)-\frac{\mu_{t+1}}{\alpha_{t+1}}\right) p_{t+1}(h)^{-\phi} \Omega_{t+1}\right] \text {. }
$$

Provided that the price setting rules can be expressed as functions of the exogenous shocks and the monetary stance, the home and foreign equilibrium entry conditions along with the exchange rate solution above comprise a three equation system in the three variables: $e, n$ and $n *$. This system admits analytical solutions for several configurations of the policy rules.

A notable property of the simplified version of the model is that the exchange rate is a function of the ratio of nominal consumption demands, hence of the monetary policy stances. To see this, recall that both economies produce the same homogeneous good with identical technology under perfect competition, and this good is traded costlessly across borders, hence arbitrage ensures that $P_{D t}=e_{t} P_{D t}^{*}$. The exchange rate then can be expressed as:

$$
e_{t}=\frac{P_{D t}}{P_{D t}^{*}}=\frac{W_{t}}{W_{t}^{*}}=\frac{P_{t} C_{t}}{P_{t}^{*} C_{t}^{*}}=\frac{\mu_{t}}{\mu_{t}^{*}}
$$

where we have used the labor supply condition (11) imposing linear preferences in leisure $(\psi=0)$. Given symmetric technology in labor input only, the law of one price implies that nominal wages are equalized (once expressed in a common currency) across the border. ${ }^{10}$

\footnotetext{
${ }^{9}$ Upon appropriate substitutions, $\Omega_{t+1}$ in equation (45) may also be written as follows $\Omega_{t+1}=\left(n_{t+1} p_{t+1}(h)^{1-\phi}+n_{t+1}^{*} p^{*}{ }_{t+1}(f)^{1-\phi} e_{t+1}{ }^{1-\phi}(1+\tau)^{1-\phi}\right)^{-1}+\left(n_{t+1} p_{t+1}(h)^{1-\phi}+n_{t+1}^{*} p^{*}{ }_{t+1}(f)^{1-\phi} e_{t+1}{ }^{1-\phi}(1+\tau)^{\phi-1}\right)^{-1}$.

${ }^{10}$ In our simplified version of the model, nominal wage equalization is due to trade in a single homogenous good whose production is not subject to shocks. A remarkable implication is that production risk is efficiently
} 


\subsection{Nominal rigidities and the equilibrium allocation}

At the core of our results is a general property of sticky price models that is best exemplified in our simplified model. Rewrite (45) as follows:

$$
p_{t+1}(h)=\frac{\phi}{\phi-1}\left\{E_{t}\left[\left(\frac{W_{t+1}}{\alpha_{t+1}}\right)\right]+\frac{\operatorname{Cov}_{t}\left[\Omega_{t+1}\left(\frac{W_{t+1}}{\alpha_{t+1}}\right)\right]}{E_{t}\left[\Omega^{\prime}{ }_{t+1}\right]}\right\}
$$

By the covariance term on the right-hand side of this expression, the optimal preset price is a function of the comovements of a firm's marginal costs $\left(W_{t+1} / \alpha_{t+1}=\mu_{t+1} / \alpha_{t+1}\right)$, and overall (domestic and foreign) demand for the firm's good, $\Omega_{t+1}$. To appreciate the relevance of this property for monetary policy, consider the extreme case of no monetary stabilization of business cycle fluctuation, i.e., posit that the monetary stance does not respond to any shock, but target a constant nominal demand in either country $\left(\mu_{t}=\mu_{t}^{*}=1\right)$. When the two countries pursue such a rule symmetrically, the nominal exchange rate remains constant at $e_{t}=\mu_{t} / \mu_{t}^{*}=1$ and, with i.i.d. shocks, there is no dynamics in predetermined variables such as prices and numbers of firms. Under the above rules, the optimal preset prices (48) simplify to

$$
p_{t+1}^{\text {nostab }}(h)=\frac{\phi}{\phi-1} E_{t}\left[\frac{1}{\alpha_{t+1}}\right] \quad p_{t+1}^{* \text { no stab }}(f)=\frac{\phi}{\phi-1} E_{t}\left[\frac{1}{\alpha^{*}{ }_{t+1}}\right],
$$

that is, prices are equal to the expected marginal costs (coinciding with the inverse of productivity) augmented by the equilibrium markup. Note that these optimal pricing decisions no longer depend on the term $\Omega$ ' (hence do not vary with trade costs and firms entry), as they do in the general case. The number of firms can be computed by substituting these prices into the entry condition (46), so to obtain:

shared, even in the absence of trade in financial assets, and independently of the way production and trade are specified in the other sector. To see this, just rewrite equation (47) as the standard perfect risk sharing condition:

$$
\frac{e_{t} P_{t}^{*}}{P_{t}}=\operatorname{rer}_{t}=\frac{C_{t}}{C_{t}^{*}} .
$$

Home consumption rises relative to foreign consumption only in those states of the world in which its relative price (i.e. the real exchange rate) is weak. 


$$
n_{t+1}^{\text {nostab }}=n_{t+1}^{* \text { no stab }}=\frac{\beta \theta}{q \phi}
$$

Intuitively, given constant monetary stances, there is no change in the exchange rate. With preset prices, a shock to productivity will have no effect on the terms of trade nor the real exchange rate, hence there will be no change in consumption demands and production for either type of good. With no monetary response, an i.i.d. shock raising productivity in the home manufacturing sector necessarily leads to a fall in the level of employment in the same sector (not compensated by a change in employment in the other sectors of the economy). Firms end up producing at low marginal costs and thus suboptimally high markups, since nominal rigidities prevent firms from re-pricing and scaling down production. Conversely, given nominal prices and demand, a drop in productivity will cause firms to produce too much at high marginal costs, hence at sub-optimally low markups. So, in a regime of no output gap stabilization, firms face random realizations of inefficiently high and inefficiently low levels of production and markup. When presetting prices, managers maximize the value of their firm by trading off higher markups in the low productivity state, with lower markups in the high productivity states. In our model above, they weigh more of the risk of producing too much at high marginal costs: it is easy to see that preset prices are increasing in the variance of productivity shocks (by Jensen's inequality, $\left.E_{t}\left[\frac{1}{\alpha_{t+1}}\right]>\frac{1}{E_{t}\left[\alpha_{t+1}\right]}=1\right) .{ }^{11}$

Since both marginal costs and overall demand are functions of monetary stances, in the general case policy regimes can critically impinge on pricing (and thus on entry) via the covariance term in the equation. The implications for our argument are detailed next.

\subsection{Prices and firm dynamics under efficient and inefficient stabilization}

Suppose that the monetary stance in each country moves in proportion to productivity in the differentiated goods sector: $\mu_{t}=\alpha_{t}, \mu_{t}^{*}=\alpha_{t}^{*}$. The exchange rate in this case is not constant, but contingent on productivity differentials, so that the home currency systematically depreciates in response to an asymmetric rise in home productivity:

\footnotetext{
${ }^{11}$ As discussed in Corsetti and Pesenti (2005) and Bergin and Corsetti (2008) in a closed economy context, given nominal demand, high preset prices allow firms to contain overproduction when low productivity squeezes markups, rebalancing demand across states of nature. High average markups, in turn, exacerbate monopolistic distortions and tend to reduce demand, production and employment on average, discouraging entry.
} 


$$
e_{t}=\frac{\alpha_{t}}{\alpha_{t}^{*}}
$$

It is easy to see that, by ensuring that the nominal marginal costs $\mu_{t} / \alpha_{t}$ remain constant, the above policy zeroes the covariance term in (48), and thus insulates the ex-post markup charged by home manufacturing firms from uncertainty about productivity. ${ }^{12}$ Note that, to the extent that monetary policy stabilizes marginal costs completely, it also stabilizes markups at their flex-price equilibrium level. It follows that the price firms preset is lower than in an economy with no stabilization:

$$
p_{t+1}^{\text {stab }}(h)=\frac{\phi}{\phi-1}<p_{t+1}^{\text {nostab }}(h)=\frac{\phi}{\phi-1} E_{t}\left[\frac{1}{\alpha_{t+1}}\right] \text {. }
$$

In a multi-sector context, a key effect of monetary stabilization is that of reducing a country's differentiated goods' price in terms of domestic non-differentiated goods, redirecting demand across sectors. This rise in demand for differentiated goods supports the entry of additional manufacturing firms.

Since the model posits that the homogenous good sector operates under perfect competition and flexible prices, there is no trade-off in stabilizing output across different sectors. It is therefore possible to replicate the flex-price allocation under a monetary policy rule that stabilizes markups in the differentiated sector. As shown in the appendix, under this rule the number of manufacturing firms is: ${ }^{13}$

$$
n_{t+1}^{\text {stab }}=\frac{\beta \theta}{q \phi} E_{t}\left[\frac{2+\left(\frac{\alpha_{t+1}}{\alpha_{t}^{*}}\right)^{1-\phi}\left((1+\tau)^{1-\phi}+(1+\tau)^{\phi-1}\right)(1+\tau)^{1-\phi}}{1+\left(\frac{\alpha_{t+1}}{\alpha_{t}^{*}}\right)^{1-\phi}\left((1+\tau)^{1-\phi}+(1+\tau)^{\phi-1}\right)(1+\tau)^{1-\phi}+\left(\frac{\alpha_{t+1}}{\alpha_{t+1}^{*}}\right)^{2(1-\phi)}}\right]
$$

the same as under flexible prices. ${ }^{14}$

\footnotetext{
12 To wit: in response to an incipient fall in domestic marginal costs domestic demand and a real depreciation boost foreign demand for domestic product. As nominal wages rise with aggregate demand, marginal costs are completely stabilized at a higher level of production. Vice versa, by curbing domestic demand and appreciating the currency when marginal costs are rising, monetary policy can prevent overheating, driving down demand and nominal wages. Again, marginal costs are completely stabilized as a result.

${ }^{13}$ Symmetric stabilization policies may or may not raise the number of firms compared to the no stabilization case; it is impossible to derive a clear-cut analytical result (see the appendix). Model simulations suggest that there is no difference for log utility, and a small positive different for CES utility with a higher elasticity of substitution. Nonetheless, we are able to provide below an analytical demonstration of asymmetric stabilization, which is our main objective.

14 The above generalizes to our setup a familiar result of the classical NOEM literature (without entry) assuming that prices are sticky in the currency of the producers (Corsetti and Pesenti $(2001,2005)$ and
} 
Contrast this allocation with the case in which, while the home government keeps stabilizing its output gap, the foreign country switches monetary regime to a currency peg:

$$
\mu_{t}=\alpha_{t} \text { and } e_{t}=1 \text {, so that } \mu_{t}^{*}=\mu_{t}=\alpha_{t}{ }^{15}
$$

Under the policy scenario just described, the optimally preset prices of domestically and foreign produced differentiated goods are, respectively:

$$
p_{t+1}(h)=\frac{\phi}{\phi-1}, \quad p_{t+1}^{*}(f)=\frac{\phi}{\phi-1} E_{t}\left[\frac{\alpha_{t+1}}{\alpha^{*}{ }_{t+1}}\right] .
$$

While the home policy makers manage to stabilize the markup of manufacturing firms completely, the foreign firms producing under the peg regime face stochastic marginal costs/markups driven by shocks to productivity wherever they occur, either in the domestic economy or abroad. With i.i.d. shocks, preset prices will be increasing in the term $\mathrm{E}_{\mathrm{t}}\left(1 / \alpha^{*}{ }_{\mathrm{t}+1}\right)$, as in the no stabilization case.

While it is not possible to solve for the number of firms in closed form, as shown in the appendix it is possible to prove that

$$
n_{t}>n_{t}^{\text {stab }}>n_{t}^{*}
$$

Other things equal, the constraint on macroeconomic stabilization implied by a currency peg tends to reduce the size of the manufacturing sector in the foreign country: there are fewer firms, each charging a higher price. The home country's manufacturing sector correspondingly expands. In other words, the country pegging its currency tends to specialize in the homogeneous good sector.

To fix ideas: insofar as the foreign peg results in higher relative prices in the foreign manufacturing sector, inefficient stabilization redirects demand towards the (now relatively cheaper) non-differentiated goods sector. Most crucially, as the ratio of the country's differentiated goods prices to non-differentiated goods prices rises compared to the home country, the foreign comparative advantage in the sector weakens: domestic demand shifts towards differentiated imports from the home country. Because of higher monopolistic distortions and the higher trade costs in imports of differentiated goods, foreign consumption falls overall (in line with the predictions from the closed economy one-sector counterpart of our model, e.g., Bergin and Corsetti 2008). All these effects combined

\footnotetext{
Devereux and Engel (2003), among others): despite nominal rigidities, policymakers are able to stabilize the output gap relative to the natural-rate, flex-price allocation.

${ }^{15}$ A related exercise consists of assuming that the foreign country keeps its money growth constant $\left(\mu_{t}^{*}=1\right)$ while home carries out its stabilization policy as above.
} 
reduce the incentive for foreign firms to enter in the differentiated goods sector. The country's loss of competitiveness is mirrored by a trend appreciation of its welfare-relevant real exchange rate, mainly due to the fall in varieties available to the consumers. Remarkably, real appreciation is actually associated with weaker, not stronger, terms of trade. Weaker terms of trade follow from the change in the composition of foreign production and exports, with more weight attached to low value added non-differentiated goods.

The consequences of a foreign peg on the home economy are specular. The home country experiences a surge of world demand for its differentiated goods production, while stronger terms of trade boost domestic consumption. More firms enter the manufacturing sector, leading to a shift in the composition of its production and exports in favor of this sector. As a result, with a foreign country passively pegging its currency, there are extra benefits for the home country from being able to pursue stabilization policies. The home manufacturing sector expands driven by higher home demand overall, and fills part of the gap in manufacturing production no longer supplied by foreign firms. At the same time, the shifting pattern of specialization ensures that the home demand for the homogeneous good is satisfied via additional imports from the foreign country.

\section{Results from the benchmark specification of the full model}

In this and the next sections, we evaluate the quantitative implications of our full model. Despite the many differences, we will show that the key results from the simplified versions of our model continue to hold in the full version. Namely, in our general specification it will still be true that, if the foreign country moves from efficient stabilization to a peg, while the home country sticks to efficient stabilization rules, (a) the foreign average markups and prices in manufacturing will tend to increase and (b) there will be production relocation - firm entry in the foreign country will fall on average, while entry in the home country will rise on average. Correspondingly, average consumption will rise at home relative to foreign. We will also show that this relocation will be associated with an average improvement in the home terms of trade (while the home welfare-relevant real exchange rate depreciates). Quantitatively, we will show that these effects are far from negligible, and that they have significant welfare implications.

The model is solved as a second order approximation around a deterministic steady state. In our simulations, nominal variables are scaled by the consumer price index, $P_{t}$, to 
allow for the possibility of a steady state inflation rate that is not zero in the Ramsey policy solution. Throughout our analysis we will assess the model predictions under four monetary policy regimes: cooperative Ramsey, inflation targeting, asymmetric currency peg and, for the purpose of comparison with data, a Taylor rule approximating historical behavior.

In the remainder of this section, we start with a discussion of our calibration and discuss results under our benchmark parameterization. We will analyze, in turn, impulse responses, unconditional means and welfare.

\subsection{Model Calibration}

Where possible, parameter values are taken from standard values in the literature. Risk aversion is set at $\sigma=2$; labor supply elasticity is set at $1 / \psi=1.9$ following Hall (2009). Parameter values are chosen to be consistent with an annual frequency - the frequency at which sectoral productivity data are available. Accordingly, time preference is set at $\beta=0.96$.

To choose parameters for the differentiated and non-differentiated sectors we draw on Rauch (1999). We choose $\theta$ so that differentiated goods represent 55 percent of U.S. trade in value. We assume the two countries are of equal size with no exogenous home bias, $v=0.5$, but allow trade costs to determine home bias ratios. To set the elasticities of substitution for the differentiated and non-differentiated goods we draw on the estimates by Broda and Weinstein (2006), classified by sectors based on Rauch (1999). The Broda and Weinstein (2006) estimate of the elasticity of substitution between differentiated goods varieties is $\phi=5.2$ (the sample period is 1972-1988). The corresponding elasticity of substitution for non-differentiated commodities is $\eta=15.3$.

The price stickiness parameter is set at $\psi_{p}=8.7$, a value which in a Calvo setting would correspond to half the firms resetting price on impact of a shock, with 75 percent resetting their price after one year. ${ }^{16}$ The firm death rate is set at $\delta=0.1$, which is four

\footnotetext{
${ }^{16}$ As is well understood, a log-linearized Calvo price-setting model implies a stochastic difference equation for inflation of the form $\pi_{t}=\beta \mathrm{E} \pi_{t+1}+\lambda m_{t}$, where $m c$ is the firm's real marginal cost of production, and where $\lambda=(1-q)(1-\beta q) / q$, with $\mathrm{q}$ is the constant probability that a firm must keep its price unchanged in any given period. The Rotemberg adjustment cost model used here gives a similar log-linearized difference equation for inflation, but with $\lambda=(\phi-1) / \kappa$. Under our parameterization, a Calvo probability of $q=0.5$
} 
times the standard rate of 0.025 to reflect the annual frequency. The mean sunk cost of entry is normalized to the value $\bar{K}=1$. The share of intermediates in differentiated goods production is set to a modest value of $\zeta=1 / 3$, though higher values will be considered in robustness checks. ${ }^{17}$

To set trade costs, we calibrate $\tau_{D}$ so that exports represent $26 \%$ of GDP, as is the average in World Bank national accounts data for OECD countries from 2000-2017. ${ }^{18}$ This requires a value of $\tau_{D}=0.33 .{ }^{19}$ This is similar to the value of trade costs typically assumed by macro research, such as 0.25 in Obstfeld and Rogoff, 2001. But it is small compared to some trade estimates, such as 1.7 suggested by Anderson and van Wincoop 2004, and adopted by Epifani and Gancia (2017). As shown later on, sensitivity analysis to a wide range of values for the trade cost suggests that our results are robust to calibrations implying trade shares both much higher and much lower than in our benchmark calibration. We begin with the standard assumption of trade models that the homogeneous good is traded frictionlessly $\left(\tau_{N}\right)$, but we will consider a range of values for this parameter also in sensitivity analysis.

The benchmark simulation model specifies entry costs in units of goods $\left(\theta_{K}=0\right)$ but we will also report results for entry costs in labor units in our sensitivity analysis (see the discussion in Cavallari, 2013). The adjustment cost parameter for new firm entry, $\lambda$, is chosen to match the standard deviation of new firm entry in the benchmark simulation to that in data. Data for the U.S. on establishment entry are available from the Longitudinal Business Database. The standard deviation for this series, logged and HP-filtered, taken as a ratio to the standard deviation of GDP for 2004-2012, is 5.53. A value of $\lambda=0.10$ in the simulation model, with the remaining parameters and shocks as described above, generates standard deviations of new firm entry close to this value. (See Table 2b.)

To our knowledge, no one else has calibrated a DSGE model with sectoral shocks distinct to differentiated and non-differentiated goods. Annual time series of sectoral

implies an adjustment cost parameter of $\psi_{P}=8.7$. This computation is confirmed by a stochastic simulation of a permanent shock raising home differentiated goods productivity without international spillovers, which implies that price adjusts $50 \%$ of the way to its long run value immediately on impact of the shock, and $75 \%$ at one period (year in our case) after the shock.

17 There is a wide range of views regarding the appropriate calibration for this parameter. Jones (2007) suggests a value of 0.43 for the share of intermediates, and it is common in the related literature to use a value at $1 / 2$. We will consider a range of values for this parameter in sensitivity analysis, but we use a modest value of this parameter for our benchmark model.

${ }^{18}$ See https://data.worldbank.org/indicator/NE.EXP.GNFS.ZS?locations=OE.

19 To coincide with standard accounting definitions, differentiated goods used as intermediates are included in the measure of exports, and excluded in the measure of GDP, as is appropriate. 
productivities are available from the Groningen Growth and Development Centre (GGDC), for the period 1980-2007. Given that we wish to isolate the asymmetries across countries that can be specifically attributed to asymmetric monetary policies, we choose to parameterize the two countries in the model symmetrically in all respects but the policy rules. So we use data for the U.S. to parameterize sectoral shocks in both the home and the foreign economy. ${ }^{20}$ Using U.S. series, sectoral TFP is calculated on a value-added basis. The differentiated goods sector comprises total manufacturing excluding wood, chemical, minerals, and basic metals; the non-differentiated goods sector comprises agriculture, mining, and subcategories of manufacturing excluded from the differentiated sector. To calculate the weight of each subsector within the differentiated (or non-differentiated) sector, we use the 1995 gross value added (at current prices) of each subsector divided by the total value added for the differentiated (or non-differentiated) sector. After taking logs of the weighted series, we de-trend each series using the HP filter. Parameters $\rho$ and $\Omega$, reported in Table 1, are obtained from running a VAR(1) on the two de-trended series. In the benchmark case, we assume no international correlation of shocks - as to clarify the way shocks transmit across borders. We will nonetheless present simulations allowing for the correlation detected in the data in our robustness analysis.

Calibration of policy parameters for the historical monetary policy Taylor rule are taken from Coenen, et al. (2008): $\gamma_{i}=0.7, \gamma_{p}=1.7, \gamma_{Y}=0.1$.

As shown in Table 2, under our benchmark calibration, the model is broadly in line with the volatility of U.S. output, as well as the volatilities of key variables (in ratio to the volatility of output), such as consumption, employment and net business formation. ${ }^{21} 22$ The moments reported in the table are generated by a stochastic simulation of the model under a Taylor policy rule specified with historical policy parameters, as discussed above.

\footnotetext{
${ }^{20}$ We note that Backus et al., 1992 similarly used a "symmetricized" parameterization of the shock process as their benchmark case for quantitative experiments in their two-country model.

${ }^{21}$ The standard deviation of the home nominal interest rate under the historical policy rule is 0.0039 in units of percentage points (where the mean level of the interest rate is 0.0417 percentage points). Under symmetric inflation targeting this standard deviation rises to 0.0106 , under foreign peg/home inflation targeting it is 0.0069 , and Ramsey policy implies a value of 0.0151 .

${ }^{22}$ Simulations are conducted for a first order approximation of the model, with output HP filtered with smoothing parameter 100 to reflect annual data.
} 
Following Ghironi and Melitz (2005), to facilitate comparison with data, Table 2 reports model simulations with units deflated using a data-consistent price index. ${ }^{23}$

\subsection{Impulse responses}

We start our study of how monetary policy can impinge on comparative advantage by analyzing the dynamic transmission of shocks under alternative monetary regimes. For our benchmark calibration, Figure 2 reports impulse response analysis. The figure shows the response of key variables to a one standard deviation positive shock to productivity in the differentiated goods sector of the home country. The figure reports results under three regimes: Ramsey optimal cooperative policies (solid line), independent inflation targeting (dashed line), and unilateral peg (dotted line).

Let's focus first on the case of independent inflation targeting (dashed line). The home policy responds to a positive productivity shock with a monetary expansion that lowers the home interest rate. This boosts domestic demand and depreciates home currency, shifting demand from foreign differentiated goods toward their home counterparts. Per effect of this policy reaction, production in the differentiated sector at home rises in line with its enhanced productivity — so far these results are in line with the literature specifying only one tradable good. Here is where our model differs: the number of home firms in the sector rises, and domestic production of tradables shifts in favor of home differentiated goods, away from non-differentiated goods. The response of the composition of production and exports is the opposite in the foreign country. While foreign production of differentiated goods falls, along with a fall in the number of foreign differentiated goods firms, non-differentiated production actually rises. The productivity shock affects the comparative advantage of the home country, which monetary policy accommodates by favoring the adjustment in relative prices across goods and borders.

The allocation under the inflation targeting regime is a key benchmark for our analysis since, as explained above, it supports the same allocation as under flexible prices. ${ }^{24}$ Policies that replicate the flexible price allocation, however, are not necessarily optimal. In

\footnotetext{
${ }^{23}$ For any variable $X_{t}$ in consumption units, we report data-consistent units as $\tilde{X}_{t}=\left(P_{t} / \tilde{P}_{t}\right) X_{t}$, where $\tilde{P}_{t}$ is an overall price index that uses a price sub-index of differentiated goods redefined as $\tilde{P}_{D, t}=\left(n_{t}+n_{t}^{*}\right)^{\frac{1}{1-\phi}} P_{D, t}$. ${ }^{24}$ Numerical experiments not shown confirm that this inflation targeting regime exactly replicates the dynamics of real variables in a flexible-price equilibrium of this model (where the price setting cost, $\psi_{P}$, is set to zero and money growth is held constant), preserving a constant markup for all the productivity shocks.
} 
our model, there are a number of distortions, in addition to sticky prices, including incomplete asset markets (leading to imperfect international risk sharing), and monopolistic markups that distort the relative price between differentiated goods on one hand, and nondifferentiated goods and leisure on the other. Further, product creation is distortionary, because markups are disconnected from the benefit of productivity to consumers.

The allocation under the optimal policy is derived from the Ramsey solution, as defined above. As shown by the solid lines in Figure 2, in the context of our model the impulse responses under Ramsey are very similar to those under inflation targeting. The fall in the home interest rate in response to the shock is almost identical- the home currency depreciation is slightly smaller under Ramsey. As for the inflation targeting case, the Ramsey policy facilitates a shift in home production toward differentiated goods and away from non-differentiated goods, and enhances the entry of home firms into the differentiated goods sector. Again, the foreign country variables move in the opposite direction. Overall, the Ramsey policy implies nearly perfect stabilization of inflation in the differentiated goods sector, with a standard deviation of just $0.2 \%$, corresponding to a standard deviation of overall inflation (including imported inflation) of $1.7 \%$. It also implies zero steady state inflation in differentiated goods prices.

This is quite different from the case in which one country commits to an exchange rate peg. To facilitate the comparison, we posit that the peg is pursue by the home country, and focus on the impulse responses after the home country shock (the dotted lines in Figure 2 ). The foreign country keeps operating under an inflation targeting regime. The impulse responses deviate sharply from the other two cases, especially in the initial periods after the shock, when the adjustment in prices is still small because of nominal rigidities. The home interest rate barely changes (as it does so only in response to policy decisions abroad), so that there is no significant stimulus of domestic demand. As a result, on impact, the home differentiated goods production rises only by a third relative to inflation targeting. The change in the number of firms, as well as in production in the non-differentiated sector is also much smaller. Clearly the commitment to a peg severely limits the ability of the Home economy to operate close to either the optimal, or the flexible price allocation benchmarks. 


\subsection{Beyond the short run: an analysis of unconditional means of macroeconomic variables}

The differences in the transmission of shocks under different policy regimes translate into differences in production, consumption and trade also in the medium to the long run. To show this, we report in Table 3 the unconditional means of key variables obtained from a second order approximation of the benchmark model. ${ }^{25}$ The first column reports means under Ramsey optimal policy, while the other four columns report the percentage difference in means relative to the Ramsey solution implied by alternative monetary policy regimes. The main contribution is in column (5), corresponding to the case in which the foreign country adopts an exchange rate peg, while the home country targets inflation.

A first important result from our numerical exercises is that the full model confirms the main insights from the simplified model in the preceding section. When the foreign country pegs its currency while the home country fully stabilizes inflation (column 5), the mean level of production of the differentiated good falls in the foreign country and rises in the home country; the foreign country instead has a higher mean level of production of the non-differentiated good. Relative to the Ramsey allocation, the share of differentiated goods in foreign exports $\left(\omega_{F}\right)$ is 4.6 percentage points lower, while the corresponding share at home $\left(\omega_{H}\right)$ is 3.9 percentage points higher. This production relocation is facilitated by a drop, by 6.8 percent, in the number of foreign firms producing differentiated goods, and a rise, by 8.3 percent, of differentiated goods firms at home.

Also consistent with the key insight from the analytical model is the mechanism initiating the production relocation: this is a shift in comparative advantage corresponding to the equilibrium adjustment in relative prices across sectors and countries. On the one hand, when the foreign country adopts a peg, home wages rise compared to foreign, driving up all prices in the economy -including the price of home differentiated goods. Indeed, compared to foreign, this price rises slightly, even after accounting for the home currency depreciation: see $\operatorname{TOTM} M_{t} \equiv p_{t}(h) /\left(e_{t} p_{t}^{*}(f)\right)$ in Table 3. On the other hand, what matters for comparative advantage is not the absolute level of prices, but the relative price of differentiated to non-differentiated goods. In the table, this relative price falls at home $(0.28$ percent $)$ while rising in foreign $(0.72$ percent $)$. In part the price adjustment stems from a

\footnotetext{
${ }^{25}$ Unconditional means are analytical, with no HP filtering applied.
} 
higher markup (by 0.10 percent) charged on average by foreign firms in the differentiated goods sector, reflecting the risk-premium-like term in the price-setting equation discussed in the previous section. In the full model used in our simulations, however, markup adjustment is compounded by a higher cost of intermediate inputs, given that foreign firms pay trade cost on the now higher imports of intermediates: the differentiated goods composite price index rises 0.73 percent abroad and only 0.07 at home. Combined, the rise in markups and the rise in marginal costs in the production of differentiated goods in foreign tilt the comparative advantage for producing and exporting these goods toward the home country.

Notably, because of the logic of comparative advantage, price competitiveness gains in the differentiated goods sector need not be in contradiction to an improvement in a country's terms of trade - as predicted by the standard monetary model. As shown in Table 3 , while the home country acquires an advantage in producing differentiated goods, its overall terms of trade (defined over the full range of goods including both differentiated and non-differentiated TOTS), improve dramatically. Note that this is so, in spite of the fact that home firms charge a lower markup on differentiated goods relative to foreign firms.

This improvement in overall terms of trade, TOTS, can partly be attributed to the rise in wages noted above. The behavior of wages highlights a qualitative difference between the full version of the model and the simplified version solved analytically in the previous section - when the labor supply is not infinitely elastic, a high level of entry tends to raise demand for labor and hence wages and production costs. Depending on the labor supply elasticity, the rise in production costs may be strong enough to prevent the international price of domestic manufacturing from falling in tandem with average markup in the differentiated goods sector-so to cause the small rise in the manufacturing terms of trade, TOTM, observed in Table 3.

The TOTS improvement is nonetheless much larger, pointing to a second and crucial effect at work, the change in the composition of exports. As foreign exports shift away from differentiated goods, the weight of these, more expensive, goods is smaller in the price index of foreign exports, but larger in the price index of foreign imports. The relevance of this result for the open macro literature should not be missed, as it reconciles a key prediction of recent monetary models, concerning the policy objective of stronger terms of trade, with policy debates typically focused on the role of monetary policy to foster price competitiveness. 
In Table 3, the second and third columns show the means implied by, respectively, the historical Taylor rule (used previously to generate standard deviations in Table 1), and a symmetric policy of full stabilization of producer price inflation in the differentiated goods sector. In both cases, there is a small drop in production of differentiated goods relative to the Ramsey solution. In the fourth column the foreign peg is paired with the historical Taylor rule at home. The effects of the peg are similar to the benchmark case (column 5), but magnitudes are smaller-e.g., the number of home firms in the differentiated goods sector rises only by $1.2 \%$, compared to $8.3 \%$ when home pursues inflation targeting. ${ }^{26}$

\subsection{Welfare analysis}

We conclude this section by discussing welfare implications. In the last three rows of Table 3, we report the effects on welfare of each alternative policy regime configuration relative to the Ramsey allocation. The change in welfare customarily is computed in terms of consumption units that households would be willing to forgo to continue under the Ramsey policy regime; that is, we compute $\Delta$ solving the following:

$$
\sum_{t=0}^{\infty} \beta^{t}\left(u\left(C_{t}^{\text {alt.policy }}, l_{t}^{\text {alt.policy }}\right)\right)=\frac{u\left[\left(1+\frac{\Delta}{100}\right)\left(C_{t}^{\text {Ramsey }}, l_{t}^{\text {Ramsey }}\right)\right]}{1-\beta} .
$$

We posit identical initial conditions across different monetary policy regimes using the Ramsey allocation, and we include transition dynamics in the computation to avoid spurious welfare reversals. ${ }^{27}$

From the table, it is apparent that the welfare consequences of adopting a peg, and hence suffering a shift in comparative advantage towards non-differentiated goods, are substantial. To wit, relative to the Ramsey rule, a foreign peg when the home country targets inflation results in a loss of welfare in foreign as high as $1.8 \%$, while the home country actually gains a striking $1.4 \%$ of consumption equivalent. The two opposing effects do not compensate each other at a global level: using equal welfare weights across countries, this asymmetric policy is worse than Ramsey by $0.20 \%$.

\footnotetext{
${ }^{26}$ We also experimented with a strict inflation targeting rule where the measure of inflation is the consumer price index rather than the differentiated goods price index. We find that when home applies this policy while foreign pegs, it does not effectively stabilize home marginal costs, and leads to a small loss in home comparative advantage in the differentiated goods sector. Under a foreign peg, the Home differentiated share falls $1.4 \%$ and home welfare falls $0.53 \%$ relative to the Ramsey policy.

${ }^{27}$ We adopt the methodology created by Giovanni Lombardo and used in Coenen et al. (2008), available from https://www.dropbox.com/s/q0e9i0fw6uziz8b/OPDSGE.zip?dl=0.
} 
From an aggregate perspective, the welfare implications of a peg are not far from the implications of adopting suboptimal symmetric targeting rules. Adopting a symmetric inflation target in both countries results in a modest loss of welfare, equal to $0.04 \%$. Instead, welfare is marginally worse when both countries adopt (suboptimal) historical rules, with losses as high as $0.25 \%$. Yet, from an individual country perspective, the effects of an asymmetric peg are more than an order of magnitude larger. ${ }^{28}$ The shift in comparative advantage in differentiated goods in favor of the home country is strongly redistributive: welfare forgone in foreign is to a large extent captured by home.

Table 3 also reports results if, while foreign pegs, home monetary authorities follow an historical policy rule. As above, home gains at the expense of foreign. But, given that the production relocation effects of historical rules are smaller, the welfare effects are less dramatic.

\section{Inspecting the mechanism}

In this and in the next section, we carry out extensive sensitivity analysis and experiment with different model specifications and parameterizations. The experiments discussed in this section are selected with a specific goal: that of highlighting which features of the model economy enable monetary policy to have non-negligible effects on comparative advantage. Towards this goal, we shut down different elements of our model one by one. First, we abstract from endogenous firm dynamics; second, we assume that all tradable goods are produced in one sector instead of two; third, we keep a two-sector specification, but assume that one of them produces nontradables; fourth we change the specification of entry costs; lastly, we shut down trade in assets. In short, the analysis to follow will demonstrate that, at different levels, all these elements lie at the core of our results, but especially the ability of the model to capture endogenous shifts in comparative advantage between two exportable goods.

For all the model specifications listed above, Table 4 reports the effect of a foreign peg on welfare and on the shares of differentiated goods exports in each country, as percentage changes relative to the Ramsey case. Column (2) refers to the case in which the number of firms is exogenous to policy. To do this, we suspend the free entry condition (equation 25) at home and in foreign, replacing it with the equations $n=n *=0.41$. This

\footnotetext{
${ }^{28}$ An improvement in home welfare relative to the Ramsey solution does not violate the principle of Ramsey optimality, as the overall world welfare under this asymmetric policy is still worse than Ramsey.
} 
specification shuts down the production relocation externality in response to differing monetary policies. As a result, the substantial asymmetries in welfare arising from the foreign peg under endogenous entry virtually disappear. Both home and foreign countries have lower welfare compared to the Ramsey case, by similar amounts. This experiment makes it clear, upfront, that an endogenous comparative advantage mechanism, such as the one we introduce in our benchmark model, is an essential building block of the mechanism generating substantial asymmetric welfare found above.

To dig deeper on this point, consider the limit case of a one sector model, where non-differentiated goods are eliminated from the model by setting $\theta$ to a value close to 1 . The model then approximates a standard sticky price model with firm entry (as in Bergin and Corsetti, 2008). The experiment is shown in column (3) of Table 3. Endogenous entry still confers the country that stabilize efficiently some advantage: the home country has higher welfare than under the Ramsey case. But the difference in welfare is an order of magnitude smaller than in the benchmark model with non-differentiated goods. Clearly the presence of two distinct tradable sectors is a necessary condition for shifts in comparative advantage to amplify the effect of monetary policy.

In column (4) the model features two sectors, but non-differentiated goods are not traded internationally $(v=1)$. This specification approximates the standard open economy model with traded and non-traded goods. Also in this case, the only margin through which monetary policy affects comparative advantage is firm dynamics. The effects from the production relocation driving our result are much muted, as they do depend upon shifts in comparative advantage between two traded sectors.

In the fifth column of the table, entry costs are in units of labor rather than in units of goods $\left(\theta_{K}=1\right)$ : the home welfare continues to benefit from the foreign peg, but the magnitude of the home welfare gain is, once again, much smaller. When entry costs are in units of differentiated goods, there is a "virtuous circle" at work that amplifies the production relocation mechanism. As home specializes in differentiated goods, a lower price index of differentiated goods reduces the entry cost for home firms. This encourages yet more home entry into the differentiated goods sector, yet greater specialization in this sector, and even lower prices.

Two features of the economy which conclusions are not sensitive to, are as follows. Column (6) suggests that results are not sensitive to the asset market specification, inasmuch as an assumption of financial autarky (hence balanced trade) delivers results 
similar to the benchmark case. This case is generated by calibrating the international bond holding cost to be prohibitively high. In fact, the magnitude of the welfare effect is even somewhat greater in this case.

By the same token, Column (7) shows that our results remain close to the benchmark specification when prices are assumed sticky in the local currency of the buyer rather than seller (to save space, equations for this model specification are presented in the appendix).

\section{Sensitivity analysis}

In this section, we complete our sensitivity analysis allowing for a wide range of calibrations for key parameters and shocks. We specifically focus on trade costs and the structure of production in a first subsection, and a variety of sources of business cycles in a second subsection.

\subsection{Trade costs and the structure of production}

Figure $3 \mathrm{a}$ shows the trade cost of differentiated goods, $\tau_{D}$, has a nonmonotonic relationship to the home welfare gain from a foreign peg: welfare gains are low both for trade costs near zero and for trade costs near unity, but rise for intermediate values, reaching a peak at around $\tau_{D}=0.3$. To see why, in Figure $3 \mathrm{~b}$ we show that there is a nearly identical hump-shaped relationship between trade costs and the degree of home specialization in differentiated goods, measured by the ratio of the number of differentiated goods firms at home and in foreign. The figure also plots, separately, the number of firms in each country, showing that a higher trade cost on differentiated goods reduces the total number of firms active in this sector. Observe that a foreign peg induces more firm entry at home than foreign at all levels of trade cost. But the difference between countries is small at both extremes of trade costs, and there is a pronounced peak around the same level of intermediate trade cost associated with a peak in home welfare.

Figure 3 offers two lessons. First, it provides clear evidence that substantial home welfare gains from a foreign peg are driven by the production relocation mechanism at the core of our analysis. Ultimately, higher home welfare comes from the fact that home consumers pay trade costs on a smaller share of differentiated goods imports: lower prices (index) translate into higher consumption. This result crucially hinges on the home country endogenously specializing in the production of differentiated goods. 
Second, Figure $3 \mathrm{~b}$ highlights the reason why the relationship between trade cost and welfare is non-monotonic, stressing the interplay of trade costs with the production relocation effect. At one extreme, high trade costs restrict the scope for international trade in differentiated goods, hence restricting the scope of production relocation. To put it simply, high trade costs mean not many differentiated goods are being traded to start with. Then, the home country cannot export as many. As trade costs become smaller and trade in differentiated goods rises, the fact that home firms have a somewhat lower price than foreign due to better monetary policy induces the virtuous cycle described above. Recall that differentiated goods are both intermediate inputs and part of a new firm entry cost. By fostering entry of home firms in differentiated goods, cheaper entry costs ultimately lower the home price index. At the other extreme, when trade costs are close to zero, it does not matter whether one buys differentiated goods domestically or from abroad; home and foreign firms have access to the same set of differentiated goods at the same price, as intermediates and/or as components of entry costs. So it is only for an intermediate range of trade costs that the virtuous cycle underlying our main results (the interaction of trade cost with intermediates prices and entry costs) becomes large.

To be clear: the benchmark calibration of the trade cost, $\tau_{D}=0.33$, was chosen to imply an export-GDP share of $26 \%$, which is the average value for OECD countries 20002017 in World Bank data. The range of $\tau_{D}$ on the horizontal axis of the Figures 3a,b maps directly into alternative trade shares. The export share implied by $\tau_{D}=0.3$, where the relocation effect reaches its maximum, is $27 \%$, which is not so different from the benchmark calibration target. However, for the case of no trade cost, $\tau_{D}=0$, the export share in GDP becomes 55\%, which is implausibly high for most countries. For a trade cost $\tau_{D}=1$, the export share falls to $13 \%$, which is the value specific to the case of U.S. data in recent years. This level of trade cost implies a substantially smaller, but still noticeable production relocation effect and welfare gain.

Our benchmark model maintains the assumption widespread in the trade literature, that the homogeneous good is traded frictionlessly. Figure 4 studies the effects of allowing for non-zero trade costs on the non-differentiated $\operatorname{good}\left(\tau_{N}\right)$. The figure suggests that the home welfare gain when foreign pegs becomes smaller and approaches zero as the trade cost for the non-differentiated sector grows relative to that of the differentiated sector. As in the trade literature on production relocation, welfare gains arise from the ability to 
reduce the trade costs paid on imported differentiated goods. If trade costs are similar across sectors, the welfare gains of specializing in a particular sector are reduced.

In light of the decisive role of trade costs, it should be clear that a roundabout production structure, by which differentiated goods require intermediates in the form of other differentiated goods, plays a role in amplifying welfare consequences of relocation. Figure 5 shows that the home welfare gain when foreign pegs consistently rises with a higher intermediates share. In fact, for an intermediate share of 0.35 , just a bit higher than our benchmark calibration, the effect on welfare rises to $2 \%$, measured in consumption units - an effect that is similar to the one discussed by Epifani and Gancia (2017). Figure 5 shows that the home welfare gain rises with yet higher intermediate shares.

The appendix explores a number of additional alternative model specifications, some of which require significant modifications in the structure of the model. These include a nontraded goods sector, an endogenously determined margin between traded and nontraded goods, as well as investment in real capital in place of a sunk entry cost. These results serve to underscore the main conclusion above, that our results arise from production relocation and shifts in comparative advantage in trade; models that narrow the scope for this channel dampen the asymmetric welfare effects of policy.

\subsection{Business cycle disturbances}

To gain further insight into the monetary transmission mechanism, we now consider a wider spectrum of sources of international business cycles. To start with, we verify the robustness of our results when productivity shocks are correlated across countries, a possibility we ruled out in the benchmark calibration. Not surprisingly, our simulations indicate that if home and foreign shocks are assumed to be perfectly correlated across countries (shocks are global), a foreign peg does not result in any production relocation. Specifically, the unconditional means of all variables remain symmetric across countries when the foreign pegs its exchange rate and home fully stabilizes differentiated goods inflation. The simple reason is that the optimal stabilization policy is symmetric across countries. As the foreign country always experiences the same shock as home, the fact that a peg requires foreign money supply and interest rates to exactly track home monetary policy is by no means less efficient than following a symmetric stabilization rule under monetary independence. 
To see how much production relocation occurs under a reasonable degree of international correlation of shock, we gather data on an aggregate of European Union countries and estimate the shock process for differentiated and non-differentiated goods joint with the U.S. data. In other words, we run a first-order vector autoregresion on the four series, two for Europe and two for the U.S., and compute the international correlations of residuals. Using the result, we set the correlation between home and foreign differentiated goods shocks equal to 0.321 , and that between non-differentiated goods shocks equal to 0.0793 . The cross-sectoral correlation, between differentiated goods in one country and non-differentiated goods in the other county is 0.0528 . Results from adopting this joint productivity shock process are reported in Table 5, column 6 . The production relocation effect is somewhat diminished but remains substantial, with the home welfare rising $1.2 \%$ rather than $1.4 \%$ relative to the Ramsey solution.

Next we extend the analysis including shocks to money demand, consumption demand, and tax shocks affecting the markup. We augment the utility function with terms to shift the marginal utility of money balances $(\chi)$ and consumption $(\zeta)$ :

$$
U_{t}=\frac{1}{1-\sigma} \zeta_{t} C_{t}^{1-\sigma}+\chi_{t} \ln \frac{M_{t}}{P_{t}}-\frac{1}{1-\psi} l_{t}^{1+\psi} .
$$

To study exogenous variations in firm markups, we adapt the shock specification used in Corsetti et al. (2010). Let $T_{D t}$ represent the fraction of differentiated goods production that is surrendered to the government, so that the differentiated goods market clearing condition becomes $\left(1-T_{D t}\right) y(h)=d_{t}(h)+\left(1+\tau_{D}\right) d_{t}^{*}(h)$. Similarly for a tax on non-differentiated goods production, $T_{N t}$, market clearing becomes $\left(1-T_{N t}\right) y_{H, t}=C_{H, t}+D_{A C, H, t}+\left(1+\tau_{N}\right)\left(C_{H, t}^{*}+D_{A C, H, t}^{*}\right)$. It is assumed that goods surrendered to the government as tax payments are consumed directly by the government, and this yields no household utility. This implies the following pricing equations for the two types of goods:

$$
\begin{aligned}
& p_{t}(h)=\frac{\phi}{(\phi-1)\left(1-T_{D t}\right)} m c_{t}+\frac{\psi_{P}}{2}\left(\frac{p_{t}(h)}{p_{t-1}(h)}-1\right)^{2} p_{t}(h)-\psi_{P} \frac{1}{\phi-1}\left(\frac{p_{t}(h)}{p_{t-1}(h)}-1\right) \frac{p_{t}(h)^{2}}{p_{t-1}(h)} \\
& +\frac{\psi_{P}}{\phi-1} E_{t}\left[\beta \frac{\Omega_{t+1}}{\Omega_{t}}\left(\frac{p_{t+1}(h)}{p_{t}(h)}-1\right) \frac{p_{t+1}(h)^{2}}{p_{t}(h)}\right]
\end{aligned}
$$

and $\quad p_{H, t}=\frac{W_{t}}{\alpha_{H, t}\left(1-T_{N t}\right)}$.

From these equations, it is apparent that the tax shocks act like a shock to firm markups. 
All shocks are assumed to follow autoregressive processes in log deviations from steady state, orthogonal to other shocks, and orthogonal across countries. The parameterization of the tax shock is taken from the estimations of Leeper et al. (2010). ${ }^{29}$ Parameterization of the consumption taste shock is taken from Stockman and Tesar (1995), and that of the money demand shock is taken from Bergin et al. (2007). ${ }^{30}$

Results are reported in Table 5. Column 2 shows that shocks to money demand are not relevant: under the monetary regimes considered in either of our experiments, any rise in money demand is automatically matched by a rise in money supply. This is true under both inflation stabilization and under a peg, as well as under the Ramsey solution. Simulations confirm that the mean number of firms and differentiated export share are unaffected, and so are the other variables in the model. Indeed, this type of shock could be potentially consequential for firms' entry only under monetary regimes, such as a constant money growth rule, that would fall short of insulating aggregate demand from destabilizing liquidity shocks, inducing a positive covariance between demand and marginal costs.

Shocks to consumption tastes, in column 3 , are found to have similar effects as productivity shocks, but are one to two orders of magnitude smaller. In the presence of taste shocks, a foreign peg discourages foreign entry in the differentiated goods sector and thereby encourages entry in the home country (that stabilizes inflation), but the magnitudes are very small.

Tax shocks instead cause firm entry and welfare to decline in both countries, more so at home than foreign. This reflects the findings in other studies (as reviewed in Corsetti et al. 2010), that cost push shocks introduce a significant trade-off between inflation and output gap stabilization, which is not necessarily optimized under inflation targeting. This underscores that what matters for production relocation is not inflation targeting per se, but a stabilization policy which is effective in stabilizing markups and therefore facilitating investment in new firms. One key lesson from the literature is that the optimal design of stabilization policy may depend on the mix of shocks.

\footnotetext{
${ }^{29}$ The process estimated by Leeper et al. (2010) for capital tax shocks is converted from a quarterly frequency to annual frequency by stochastic simulation of the process and then fitting an annual sampling of the artificial data to a first order autoregression. The resulting autoregressive parameter of 0.741 and standard deviation of shocks of 0.0790 are applied to tax shocks in each country and each sector. These shocks are assumed orthogonal to each other. The mean level of this tax, 0.184, also is taken from Leeper et al. (2010).

${ }^{30}$ We follow the first experiment of Stockman and Tesar (1995), in parameterizing a shock to overall consumption with standard deviation 2.5 times that of productivity, and with the same autoregressive parameter as productivity. We follow Bergin et al. (2007) in setting the standard deviation of the money demand shock at 0.030 , with a serial correlation of 0.99 .
} 
We conclude with an experiment combining all four shocks, shown in column (5). The overall effects on export shares and welfare are close to the sum of the effects under productivity and tax shocks treated separately earlier in the table. Relative to Ramsey, the home country has higher welfare, the foreign lower welfare, but the home gain is smaller than under the benchmark model with productivity shocks only.

\section{Conclusion}

According to a widespread view in policy and academic circles, monetary and exchange rate policy has the power to favor, or hinder, the competitiveness of domestic producers, mainly by affecting the level of the exchange rate. This paper revisits the received wisdom on this issue, exploring a new direction for open-economy monetary models. Our argument is that what matters is the firms' production and investment response to macroeconomic stabilization regimes, rather than the response to specific measures depreciating (or failing to depreciate) the exchange rate in the short run.

It is widely accepted that monetary policy may have differential effects across sectors. Building on this observation, we work out a model to explore potential effects of monetary policy on the comparative advantage of a country in producing goods with the characteristics (high upfront investment, monopoly power and nominal frictions) typical of manufacturing. Our main conclusion is that a stabilization regime delivering an efficient stabilization of the output gap (and marginal costs) can strengthen a country's comparative advantage in the production of these goods beyond the short run.

To be clear, an efficient stabilization policy requires contingent expansions and contractions, which may foster but also reduce the international price competitiveness of a country ex post. Our results suggest that, depending on these state-contingent responses to business cycle shocks, monetary stabilization may affect the comparative advantage of a country in a way that is separate from the prescription of pro-competitive devaluations familiar from traditional policy models. By stabilizing demand and markups, an efficient stabilization policy may foster entry in sectors where firms' value is more sensitive to uncertainty, essentially because of the combination of high upfront costs and nominal rigidities. Failing to stabilize demand, on the contrary, may discourage entry and production in these sectors.

As our conclusions point to medium to long-run non-neutrality of money, we should stress that they are perfectly in line with the classical literature. In the classic 
literature stressing the shoe-leather costs of inflation, an inefficient monetary policy (failing to deliver low inflation) has steady state effects, in that it magnifies wasteful costs of cash management at household and firm level. In the new Keynesian literature, suboptimal policy creates price dispersion that has real misallocation costs in the medium to the long run. In the same vein, we call attention to a different, potentially consequential implication of policies that fail to stabilize the output gap in terms of their adverse medium-term effects on the structure of production and exports.

To illustrate our point, we focus our analysis on the inefficiency of currency pegs, but our results generalize to other forms of inefficiency due to constraints on monetary policy (a secular stagnation), or suboptimal rules (such as non-contingent money growth rules). Nevertheless, we should highlight that our study of unilateral pegs bears relevant lessons for asymmetric monetary unions, whereas the common policy stance may not be appropriate from individual member states' perspectives. One lesson is straightforward. Experience suggests that member states may try to enter a union at a competitive level of the exchange rate, that temporarily enhances external demand (but also feeds price and hence inflation adjustment). Over time, nonetheless, the loss of monetary independence and the exchange rate as adjustment margin is bound to affect the production structure and competitiveness, unless the country activates alternative policy instruments that can make up for such a loss and deliver efficient stabilization. If anything, our results strengthen the case for fiscal policy and reform in the product, labor and credit markets as a precondition for a successful monetary union.

Finally, this paper contributes an important result to the New Keynesian literature. One of the key findings from this literature is that monetary policy trades off output gap stabilization with stronger terms of trade. In our model, we show how this trade-off is inherent in monetary models featuring comparative advantage. To the extent that efficient stabilization makes manufacturing more competitive, this results in a shift in the sectoral allocation of resources and composition of exports. It is this shift that improves the country's overall terms of trade, even if the international price of domestic manufacturing falls. Overall, the theory developed in this paper points to new promising directions for integrating trade and macro models and brings the literature closer to addressing core concerns in the policy debate. 


\section{References}

Anderson, James E. and Eric van Wincoop, 2004. "Trade Costs," Journal of Economic Literature 42, 691-751.

Backus, David K., Patrick J. Kehoe and Finn E. Kydland, 1992. "International Real Business Cycles," Journal of Political Economy 100, 745-775.

Benigno, Gianluca and Pierpaolo Benigno, 2003. "Price Stability in Open Economies," Review of Economic Studies 70, 743-764.

Bergin, Paul R. and Giancarlo Corsetti, 2008. "The Extensive Margin and Monetary Policy," Journal of Monetary Economics 55, 1222-1237.

Bergin, Paul R., Hyung-Cheol Shin, and Tchakarov, 2007. "Does Exchange Rate Variability Matter for Welfare? A Quantitative Investigation of Stabilization Policies," European Economic Review 51(4), 1041-1058.

Bilbiie, Florin O., Fabio Ghironi, and Marc J. Melitz, 2008. "Monetary Policy and Business Cycles with Endogenous Entry and Product Variety," in Acemoglu, D., K. S. Rogoff, and M. Woodford, eds., NBER Macroeconomics Annual 2007, Univ. of Chicago Press, Chicago, 299-353.

Bodenstein, Martin, Luca Guerrieri, and Lutz Kilian, 2012. "Monetary Policy Responses to Oil Price Fluctuations," IMF Economic Review 60, 470-504.

Broda, Christian and David E. Weinstein, 2006. "Globalization and the Gains from Variety," The Quarterly Journal of Economics 121, 541-585.

Campolmi, Alessia, Harald Fadinger, and Chiara Forlati, 2014. "Trade Policy: Home Market Effect versus Terms-of-trade Externality,” Journal of International Economics 93, 92-107.

Canzoneri, Matthew B. Robert E. Cumby and Behzad Diba, 2005. "The Need for International Policy Coordination; What's Old, What's New, What's Yet To Come?" Journal of International Economics 66, 363-384.

Cavallari, Lilia, 2013. "Firms' Entry, Monetary Policy and the International Business Cycle," Journal of International Economics 91, 263-274.

Coenen, Guenter, Giovanni Lombardo, Frank Smets and Roland Straub, 2008. "International Transmission and Monetary Policy Cooperation," ECB Working Paper no. 858.

Corsetti, Giancarlo, Luca Dedola, and Sylvain Leduc, 2010. "Optimal Monetary Policy in Open Economies," Handbook of Monetary Economics, vol III, ed by B. Friedman and M. Woodford, 861-933.

Corsetti, Giancarlo, Philippe Martin and Paolo Pesenti, 2007. "Productivity, Terms of Trade and the 'Home Market Effect'," Journal of International Economics 73(1), 99-127.

Corsetti, Giancarlo, and Paolo Pesenti, 2001. "Welfare and Macroeconomic Interdependence," Quarterly Journal of Economics 116, 421-446.

Corsetti, Giancarlo, and Paolo Pesenti, 2005. "International Dimensions of Optimal Monetary Policy," Journal of Monetary Economics 52(2), 281-305.

Cunat, Alejandro and Marc Melitz, 2012. "Volatility, Labor Market Flexibility, and the Pattern of Comparative Advantage," Journal of the European Economic Association 10, 225-254. 
Devereux, Mick and Charles Engel, 2003. "Monetary Policy in the Open Economy Revisited: Price Setting and Exchange Rate Flexibility," Review of Economic Studies 70, 765-783.

Epifani, Paolo and Gancia, Gino, 2017. "Global Imbalances Revisited: The Transfer Problem and Transport Costs in Monopolistic Competition," Journal of International Economics 108, 99-116.

Fernández-Villaverde, Jesús, Pablo Guerrón-Quintana, Juan F. Rubio-Ramírez, and Martin Uribe, 2011. "Risk Matters: The Real Effects of Volatility Shocks," American Economic Review 101, 2530-2561.

Ghironi, Fabio and Marc J. Melitz, 2005. "International Trade and Macroeconomic Dynamics with Heterogeneous Firms," The Quarterly Journal of Economics 120(3), 865-915.

Hall, Robert E., 2009. "By How Much Does GDP Rise If the Government Buys More Output?” Brookings Papers on Economic Activity 2, 183-231.

Helpman, Elhanan and Paul Krugman, 1989. Trade Policy and Market Structure, MIT Press.

Jones, Charles I., 2007. "Input-Output Multipliers, General Purpose Technologies, and Economic Development.” Unpublished manuscript, http://wwwleland.stanford.edu/ chadj/io026.pdf.

Krugman , Paul, 1980. "Scale Economies, Product Differentiation, and the Pattern of Trade," American Economic Review 70, 950-959.

Leeper, Eric M., Michael Plante, and Nora Taum, 2010. "Dynamics of Fiscal Financing in the United States," Journal of Econometrics 156, 304-321.

Lombardo, Giovanni and Federico Ravenna, 2014. "Openness and Optimal Monetary Policy," Journal of International Economics 93, 153-172.

Nakov, Anton, and Andrea Pescatori, 2010a. "Monetary Policy Trade-Offs with a Dominant Oil Producer," Journal of Money, Credit, and Banking 42, 1-32.

Nakov, Anton, and Andrea Pescatori, 2010b. "Oil and the Great Moderation," Economic Journal 120, 131-156.

Nunn, Nathan, 2007. "Relationship-Specificity, Incomplete Contracts, and the Pattern of Trade," The Quarterly Journal of Economics 122, 569-600.

Obstfeld, Maurice and Kenneth Rogoff, 2000. "New Directions for Stochastic Open Economy Models," Journal of International Economics 50, 117-154.

Obstfeld, Maurice and Rogoff, Kenneth, 2001. "The Six Major Puzzles in International Macroeconomics: Is There a Common Cause?" in: NBER Macroeconomics Annual 2000, Volume 15, pages 339-412 National Bureau of Economic Research, Inc.

Ossa, Ralph, 2011. “A "New Trade” Theory of GATT/WTO Negotiations," Journal of Political Economy 119, 122-152.

Rauch, James E., 1999. "Networks Versus Markets in International Trade," Journal of International Economics 48, 7-35.

Stockman, Alan C. and Linda Tesar, 1995. "Tastes and Technology in a Two-Country Model of the Business Cycle: Explaining International Comovements," American Economic Review 85(1), 168-85. 
$\underline{\text { Preferences }}$

Table 1. Benchmark Parameter Values

Risk aversion

Time preference

Labor supply elasticity

Differentiated goods share

Non-differentiated goods home bias

Differentiated goods elasticity

Non-differentiated goods elasticity

$$
\begin{aligned}
& \sigma=2 \\
& \beta=0.96 \\
& 1 / \psi=1.9 \\
& \theta=0.61 \\
& v=0.5 \\
& \phi=5.2 \\
& \eta=15.3
\end{aligned}
$$

\section{Technology}

Firm death rate

Price stickiness

$$
\delta=0.1
$$$$
\psi_{P}=8.7
$$

Intermediate input share

$\varsigma=0.33$

Differentiated goods trade cost

$\tau_{D}=0.33$

Non-differentiated goods trade cost

$\tau_{N}=0$

Mean sunk entry cost

$\bar{K}=1$

Firm entry adjustment cost

$\lambda=0.10$

Bond holding cost

$$
\psi_{B}=0.001
$$

Monetary Policy (for the historical policy rule):
Interest rate smoothing
$\gamma_{i}=0.7$
Inflation response
$\gamma_{p}=1.7$
GDP response
$\gamma_{Y}=0.1$

Shocks:
$\rho=\left[\begin{array}{ll}0.4132 & 0.1379 \\ 0.0057 & 0.2574\end{array}\right]$
$E\left[\varepsilon_{t} \varepsilon_{t}^{\prime}\right]=\left[\begin{array}{ll}5.23 e-4 & 1.70 e-4 \\ 1.70 e-4 & 8.16 e-4\end{array}\right]$

Table 2. Standard Deviations (percent)

\begin{tabular}{lcc} 
& $\begin{array}{c}\text { Data } \\
\text { (U.S.) }\end{array}$ & $\begin{array}{c}\text { Historical policy } \\
\text { rule }\end{array}$ \\
\hline GDP & 2.07 & 2.49 \\
\multicolumn{2}{l}{ as ratios to std. dev. of GDP: } \\
Firm creation & 5.53 & 4.06 \\
Consumption & 0.75 & 0.29 \\
Labor & 0.87 & 0.88 \\
\hline
\end{tabular}


Table 3. Means: Comparison Across Policy Regimes

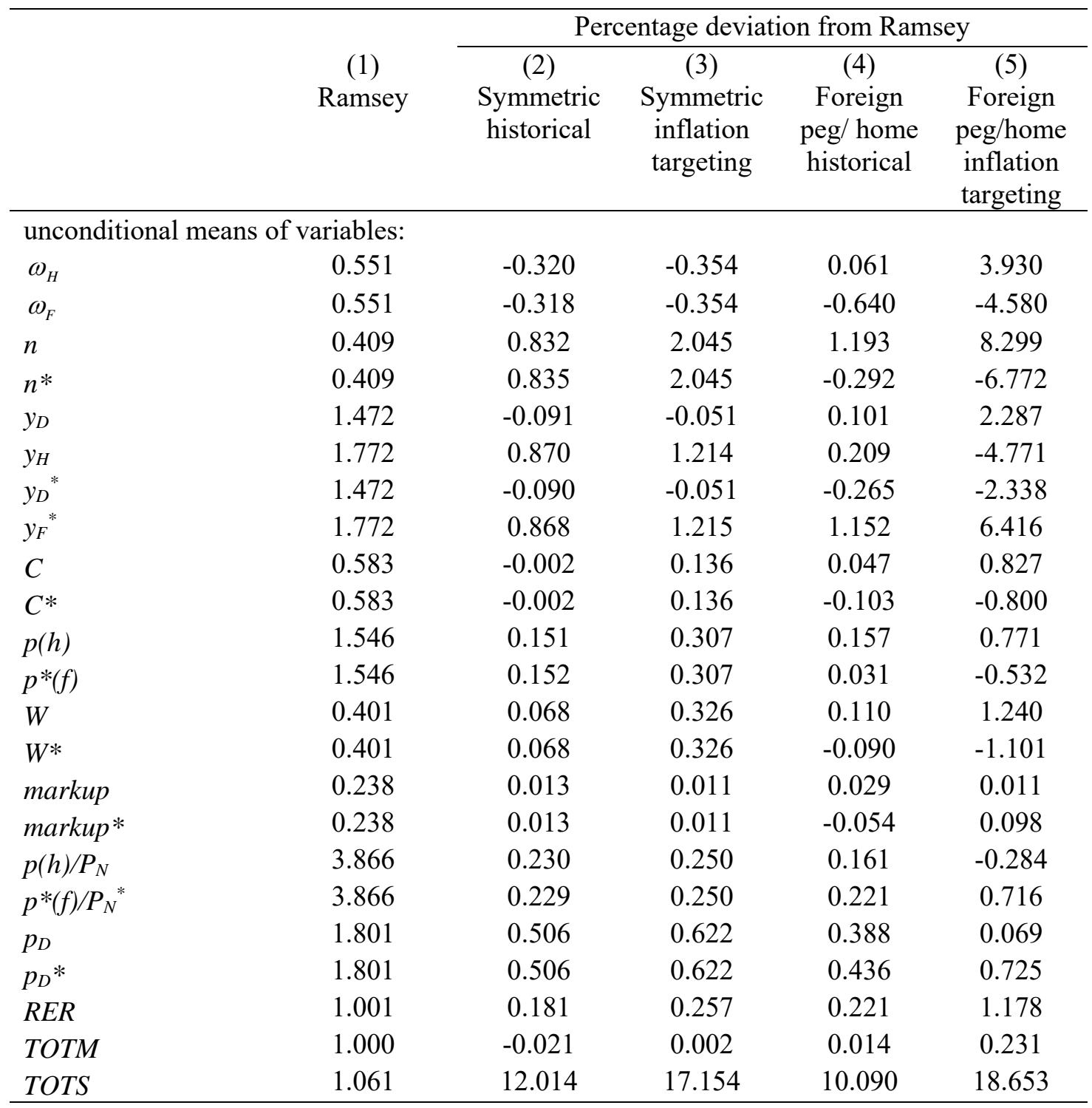

Welfare relative to Ramsey policy, percent difference in consumption units, conditional on initial conditions

\begin{tabular}{lcccc} 
total & -0.246 & -0.041 & -0.259 & -0.202 \\
home & -0.246 & -0.041 & -0.105 & 1.390 \\
foreign & -0.246 & -0.041 & -0.412 & -1.807 \\
\hline
\end{tabular}

Results come from a second-order approximation to the model. $\omega_{H}$ represents the share of differentiated goods in overall exports of the home country, and it is computed

$\omega_{H, t} \equiv \frac{p_{t}^{*}(h) n_{t-1}\left(c_{t}^{*}(h)+d_{K, t}^{*}(h)+d_{A C, t}^{*}(h)\right)}{p_{t}^{*}(h) n_{t-1}\left(c_{t}^{*}(h)+d_{K t}^{*}(h)+d_{A C, t}^{*}(h)\right)+P_{H, t}^{*}\left(C_{H, t}^{*}+D_{A C, H, t}^{*}\right)} ; \omega_{F}$ represents the counterpart for the foreign country. Since $\omega_{H}$ and $\omega_{F}$ are in percentage form already, the table reports differences from Ramsey policy for these two variables in units of percentage points. Home markup is calculated as markup = $(p(h) / m c-1) * 100$; analogous for foreign. 
Table 4. Alternative Model Specifications (percent difference of foreign peg from Ramsey)

\begin{tabular}{|c|c|c|c|c|c|c|c|}
\hline & Benchmark & $\begin{array}{l}\text { Fixed num. } \\
\text { firms } \\
\left(n=n^{*}=0.41\right)\end{array}$ & $\begin{array}{c}(3) \\
\text { No non- } \\
\text { diff. } \\
\text { goods } \\
(\theta=1)\end{array}$ & $\begin{array}{c}(4) \\
\text { No trade } \\
\text { in non- } \\
\text { diff. } \\
\text { goods } \\
(v=1) \text { : }\end{array}$ & $\begin{array}{c}(5) \\
\text { Entry } \\
\text { cost in } \\
\text { labor } \\
\text { units } \\
\left(\theta_{\mathrm{K}}=1\right)\end{array}$ & $\begin{array}{l}\text { Balanced } \\
\text { trade } \\
\left(\psi_{\mathrm{B}}=1000\right)\end{array}$ & $\begin{array}{c}\text { (7) } \\
\text { Local } \\
\text { currency } \\
\text { pricing }\end{array}$ \\
\hline \multicolumn{8}{|l|}{ Welfare: } \\
\hline Home & 1.390 & -0.144 & 0.072 & 0.042 & 0.078 & 1.492 & 1.370 \\
\hline Foreign & -1.807 & -0.190 & -0.232 & -0.247 & -0.163 & -1.957 & -1.641 \\
\hline Total & -0.202 & -0.167 & -0.080 & -0.103 & -0.042 & -0.226 & -0.477 \\
\hline \multicolumn{8}{|c|}{ Diff. goods export share: } \\
\hline Home & 3.930 & -0.134 & 0.000 & 0.000 & 0.728 & 8.212 & 6.126 \\
\hline Foreign & -4.580 & -0.019 & 0.000 & 0.000 & 0.213 & -8.358 & -6.441 \\
\hline
\end{tabular}

Table 5. Alternative Shocks

(percent difference of foreign peg from Ramsey)

\begin{tabular}{|c|c|c|c|c|c|c|}
\hline & (1) & (2) & (3) & (4) & $(5)$ & (6) \\
\hline & $\begin{array}{l}\text { Productivity } \\
\text { (benchmark) }\end{array}$ & $\begin{array}{l}\text { Money } \\
\text { demand }\end{array}$ & Tastes & Tax & $\begin{array}{c}\text { All four } \\
\text { shocks }\end{array}$ & $\begin{array}{c}\text { Correlated } \\
\text { productivity } \\
\text { shocks }\end{array}$ \\
\hline \multicolumn{7}{|l|}{ Welfare: } \\
\hline Home & 1.390 & 0.000 & 0.012 & -1.113 & 0.363 & 1.174 \\
\hline Foreign & -1.807 & 0.000 & -0.055 & -0.236 & -2.113 & -1.409 \\
\hline Total & -0.202 & 0.000 & -0.022 & -0.674 & -0.871 & -0.114 \\
\hline \multicolumn{7}{|c|}{ Diff. goods export share: } \\
\hline Home & 3.930 & 0.000 & 0.057 & -6.318 & 4.494 & 3.260 \\
\hline Foreign & -4.580 & 0.000 & -0.116 & -0.065 & -3.421 & -3.761 \\
\hline
\end{tabular}

Welfare computed as percent difference from Ramsey case, in units of steady state consumption, conditional on Ramsey policy allocation as initial conditions. Differentiated goods share of exports $\left(\omega_{H}\right.$ and $\omega_{F}$ ) are in percentage form already, so the table reports differences from Ramsey policy in units of percentage points. Values based on unconditional means from simulation of second order approximation of the model. 
Figure 1. Aggregation for Home Consumption

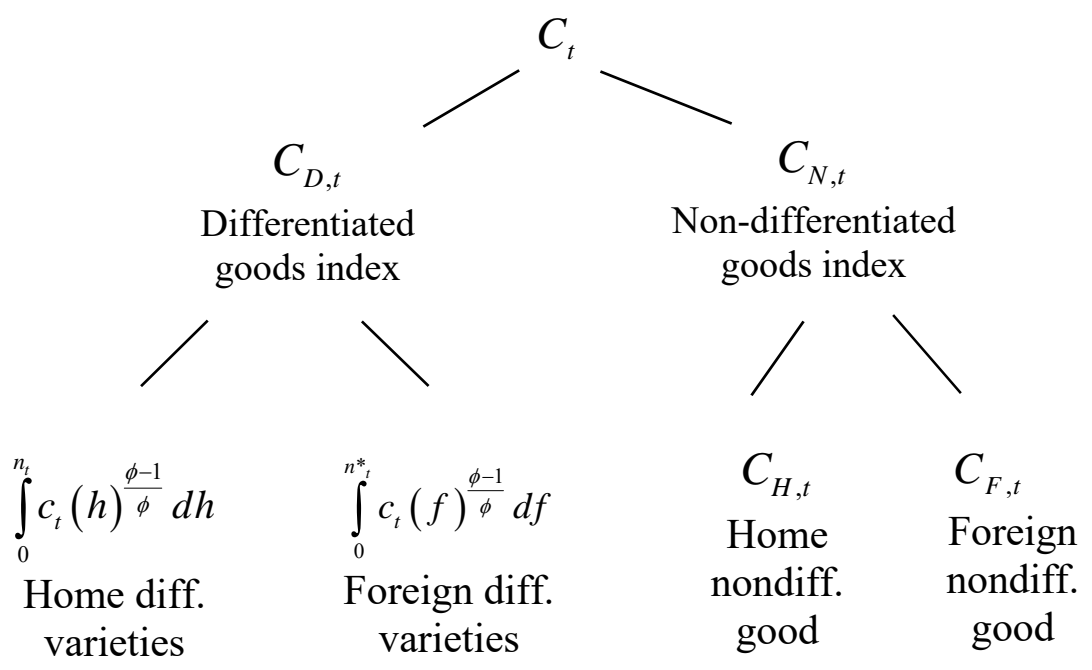


Figure 2. Impulse responses to a 1 standard deviation rise in home manufacturing productivity, under various policies
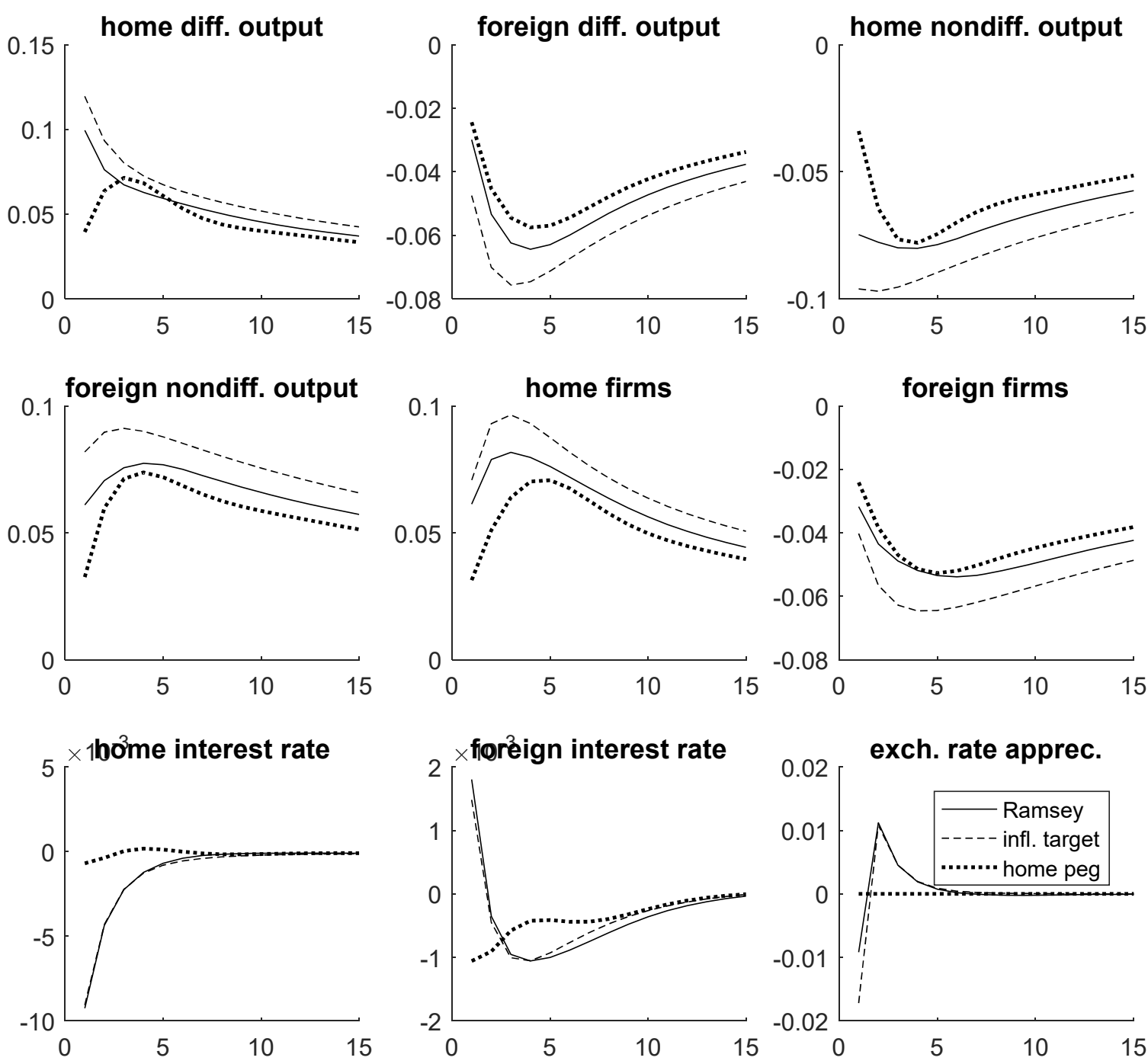

Vertical axis is percent deviation $(0.01=1 \%)$ from steady state levels. Horizontal axis is time (in years). 
Figure 3a. Effect of trade cost of differentiated goods on the home welfare gain from foreign peg

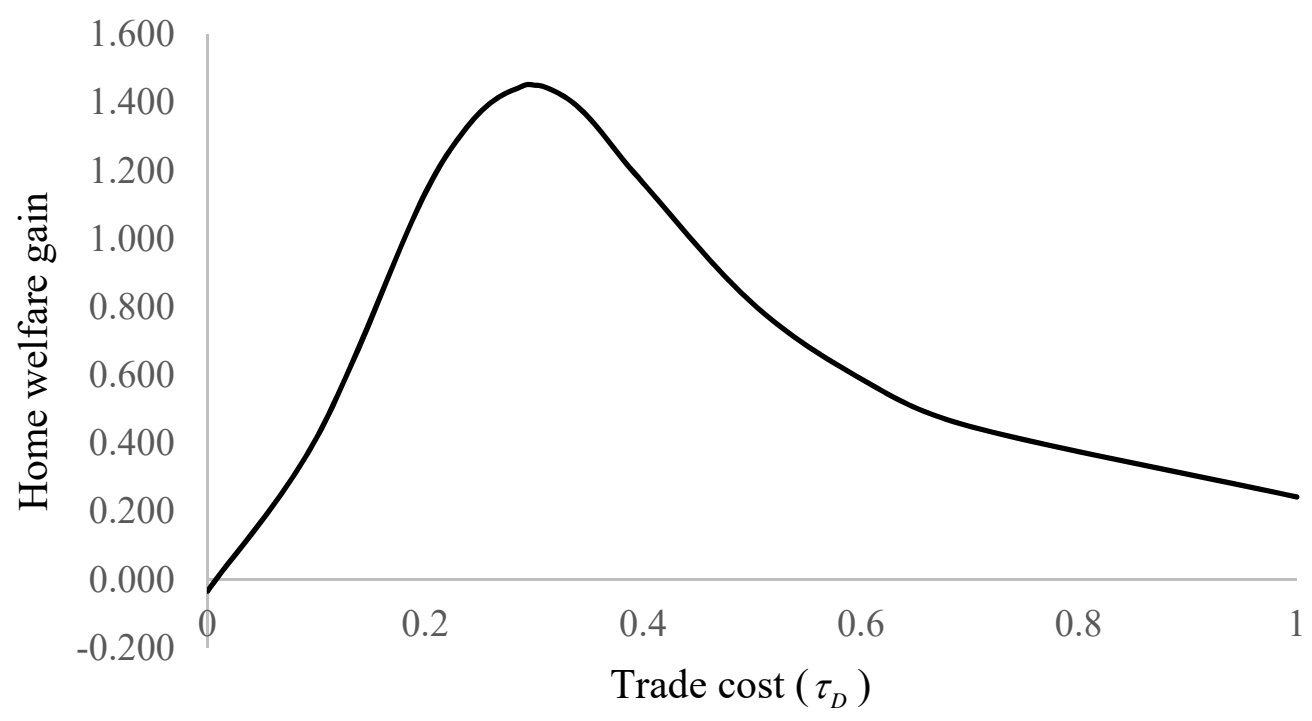

Home welfare gain is percentage difference from Ramsey policy welfare, in consumption units.

Figure 3b. Effect of trade cost of differentiated goods on numbers of firms

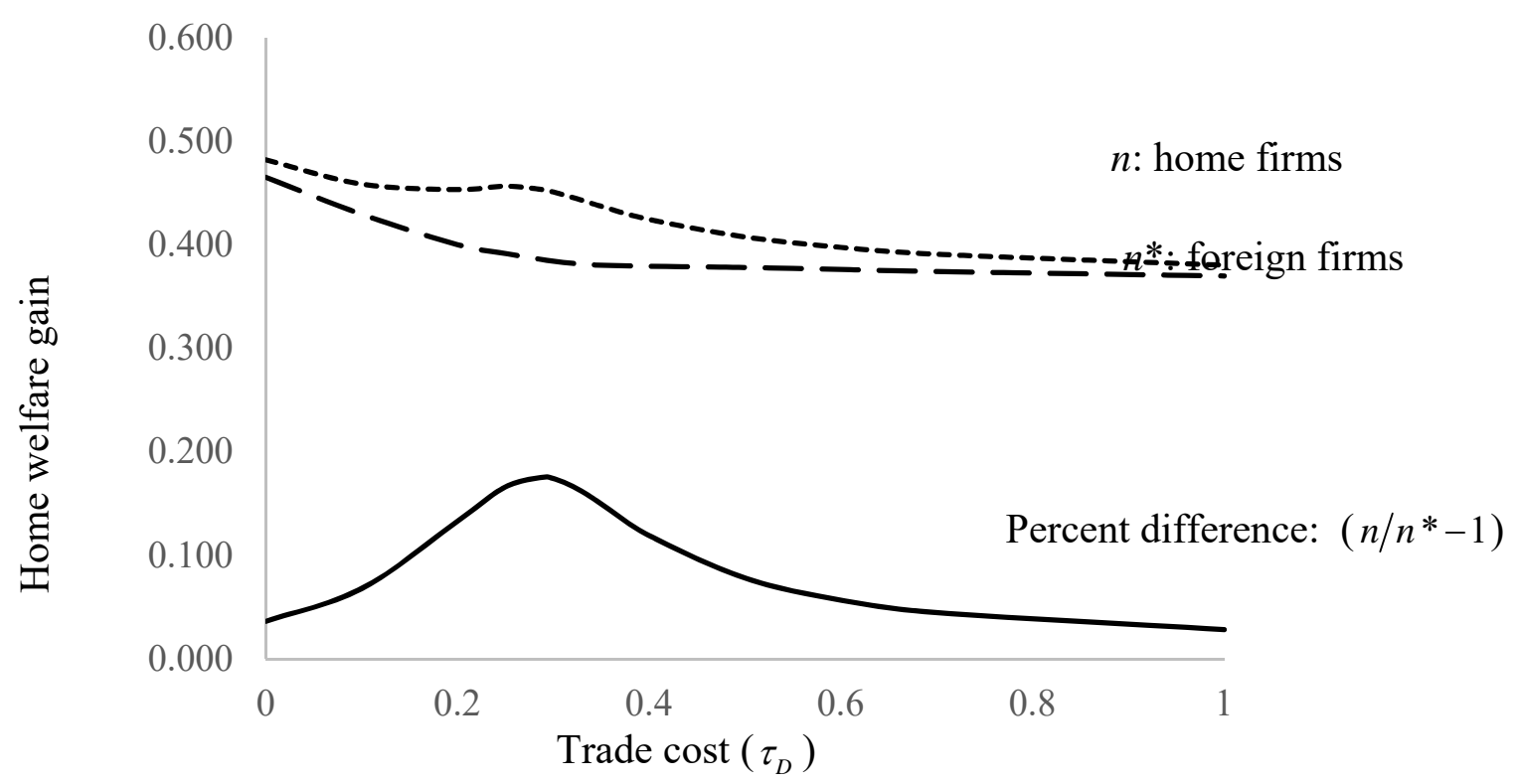

Home welfare gain is percentage difference from Ramsey policy welfare, in consumption units. 
Figure 4. Effect of trade cost of non-differentiated goods on the home welfare gain from foreign peg

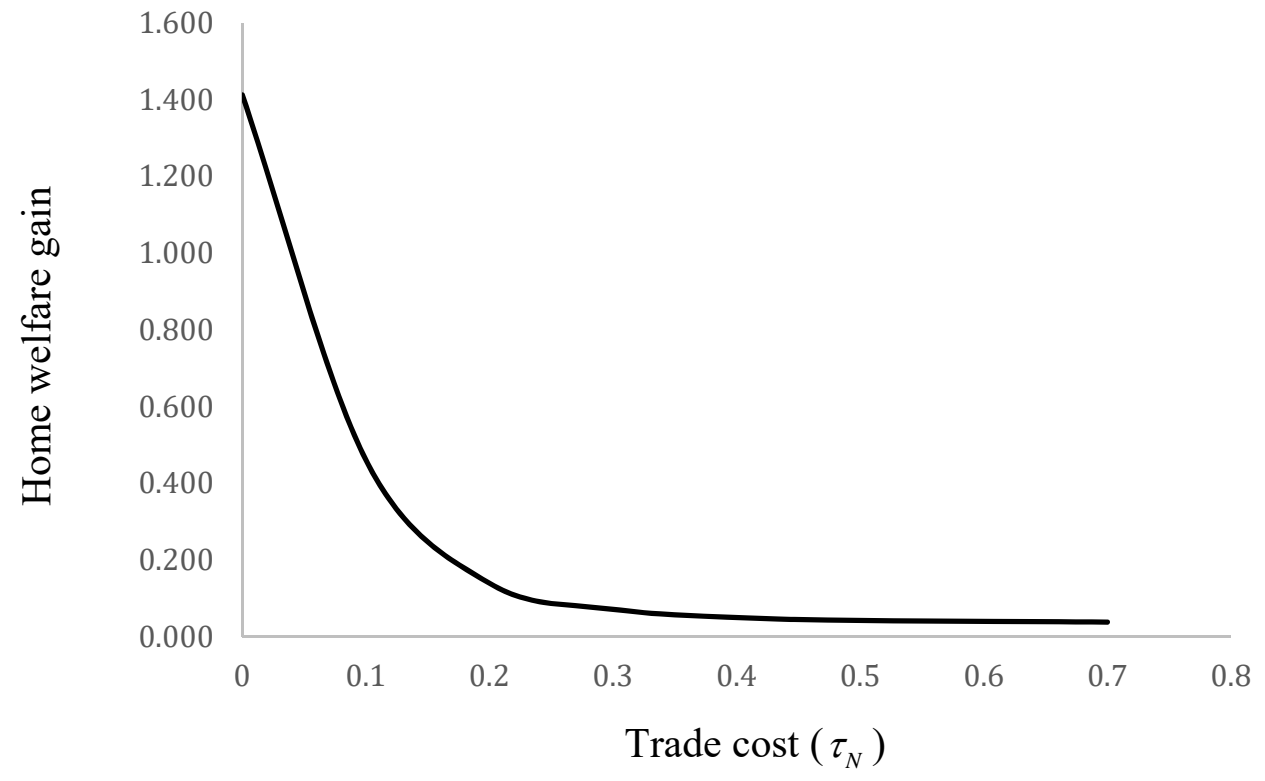

Home welfare gain is percentage difference from Ramsey policy welfare, in consumption units.

Figure 5. Effect of intermediate input share on the home welfare gain from foreign peg

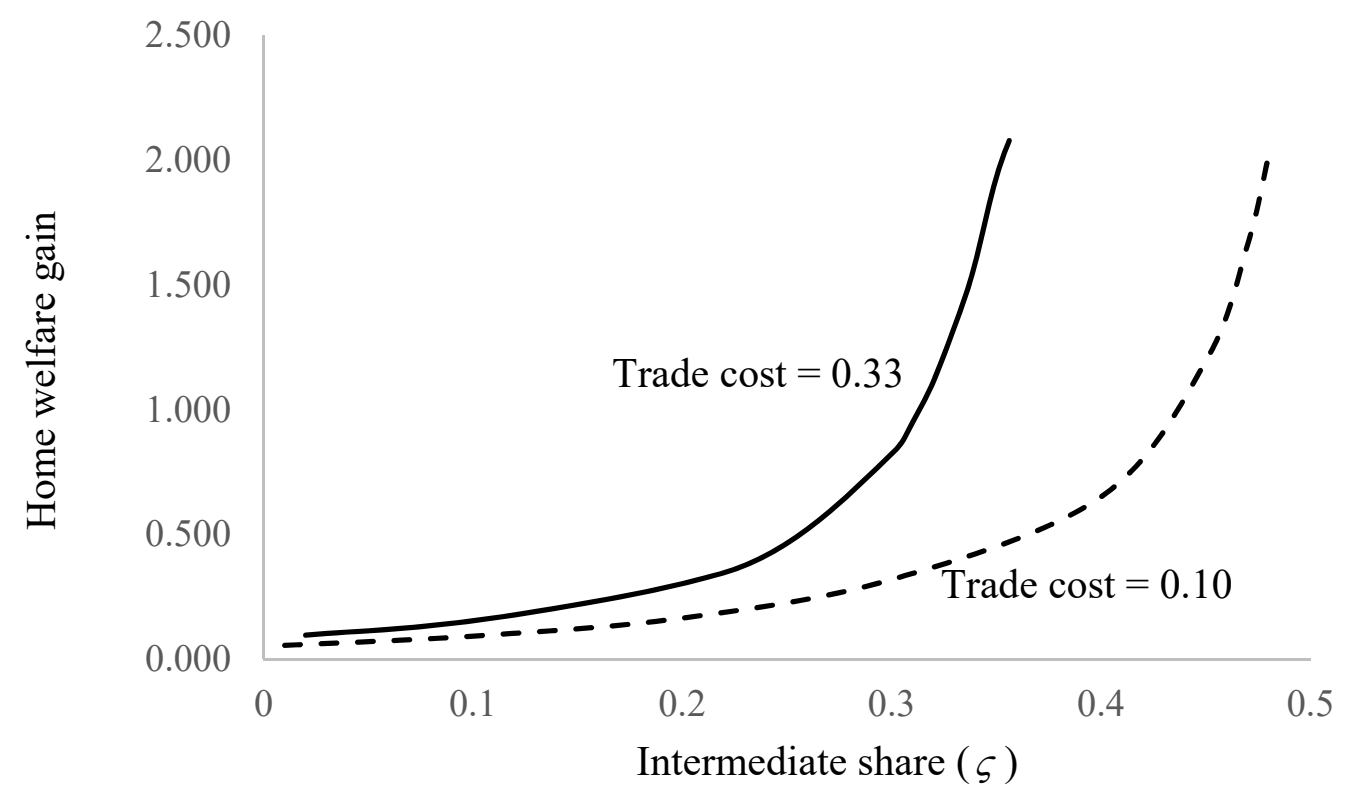

Home welfare gain is percentage difference from Ramsey policy welfare, in consumption units. 